\title{
Perimitochondrial Enzymatic Self-Assembly for Selective Targeting the Mitochondria of Cancer Cells
}

\author{
Hongjian He, Xingyi Lin, Jiaqi Guo, Jiaqing Wang, and Bing Xu*
}

\begin{abstract}
Emerging evidence indicates that mitochondria contribute to resistance in cancer. But how to selectively target the mitochondria of cancer cells remains less explored. Here we show perimitochondrial enzymatic self-assembly for selectively targeting the mitochondria of liver cancer cells. Micelles of a peptide-lipid conjugate, being a substrate of enterokinase (ENTK), encapsulate chloramphenicol (CLRP), a clinically used antibiotic that is deactivated by glucuronidases in cytosol, but not in mitochondria. Perimitochondrial ENTK cleaves the Flag-tag on the conjugate to deliver CLRP selectively into the mitochondria of cancer cells, thus inhibiting the mitochondrial protein synthesis, inducing the release of cytochrome $\mathrm{c}$ into cytosol, and resulting in cancer cell death. This strategy selectively targets liver cancer cells over normal liver cells. Moreover, blocking the mitochondrial protein synthesis sensitizes the cancer cells, relying on glycolysis and/or OXPHOS, to cisplatin. For the first time, this work illustrates a facile approach, selectively targeting mitochondria of cancer cells and repurposing clinically approved ribosome inhibitors, to interrupt the metabolism of cancer cells for cancer treatment.
\end{abstract}

\section{Table of Contents}

Table of Contents 1

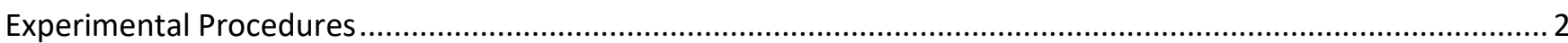

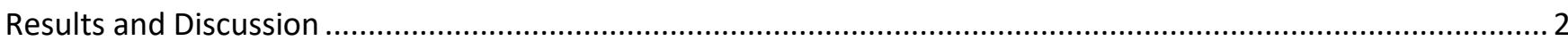

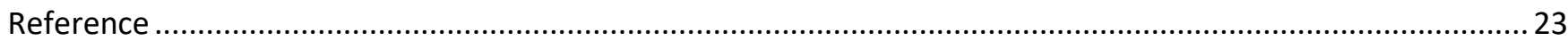

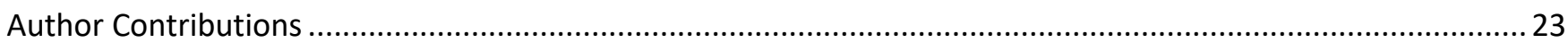




\section{Experimental Procedures}

Materials. All amino acid derivatives involved in the synthesis were purchased from GL Biochem (Shanghai) Ltd. N, Ndiisopropylethylamine (DIPEA) and O-benzotriazole-N,N,N',N'-tetramethyluronium-hexafluorophosphate (HBTU) were purchased from Fisher Scientific. The synthesis of all peptide fragments was based on solid-phase peptide synthesis (SPPS). The peptides were made via the combination of SPPS and solution phase synthesis. All crude compounds were purified by HPLC with the yield of 70-80\%. All reagents and solvents were used as received without further purification unless otherwise stated. All cell lines were purchased from ATCC. All media for cell culture were purchased from ATCC, fetal bovine serum (FBS) and penicillin/streptomycin from Gibco by Life technologies, and 3-(4,5-Dimethylthiazol-2-yl)-2,5-diphenyltetrazolium bromide (MTT) from ACROS Organics. Mitochondria isolation kit was purchased from Thermo Fisher Scientific. The mitochondria were isolated according to the protocol provided by the company. All antibodies were purchased from Abcam.

Instruments. All peptides were purified by Water Agilent 1100 HPLC system, equipped with an XTerra C18 RP column. LC-MS was operated on a Waters Acquity Ultra Performance LC with Waters MICRO-MASS detector. Transmission electron microscope (TEM) images were taken on Morgagni 268 transmission electron microscope. Fluorescent analysis was performed on Shimadzu RF-5301PC fluorescence spectrophotometer. Fluorescence images were taken by ZEISS LSM 880 confocal laser scanning microscope.

Peptide Synthesis. The synthesis of Flag-tag-Gly-OH was done by Fmoc-based solid phase synthesis. The synthesis route of Flag$(\mathrm{C} 16)_{2}$ and its derivatives were shown in Scheme S2 to S4. Briefly, the carboxylic groups in Fmoc-Glu-OH were activated by a mixture (1:1 molar ratio) of DCC and NHS in the presence of triethylamine (TEA) at room temperature for $30 \mathrm{~min}$. After the activation, $\mathrm{NH}_{2}-\mathrm{C}_{16}$ or $\mathrm{NH}_{2}-\mathrm{C} 14-\mathrm{NBD}$ were mixed into the solution. The mixtures were kept at room temperature for overnight. Piperidine was used to remove the Fmoc protection group. HPLC was used to purify the resulted lipids. The C-terminus in the Flag-tag-Gly-OH was activated by DCC and NHS in the presence of TEA at room temperature for $30 \mathrm{~min}$. After the activation, the synthesized lipids were mixed into the Flag-tag solution. The mixtures were incubated at room temperature for overnight. Piperidine and trifluoroacetic acid were used to remove all protection groups. HPLC was used to purify the final products.

Cell Culture. HeLa and HepG2 cells were cultured in Minimum Essential Medium (MEM) supplemented with $10 \%$ (vol/vol) FBS, 0.5\% ( $\mathrm{vol} / \mathrm{vol})$ penicillin (10, 000 unit), and $0.5 \%$ (vol/vol) streptomycin (10, 000 unit). HS-5 cells were cultured in Dulbecco's Modified Eagle Media (DMEM) supplemented with 10\% (vol/vol) FBS, $0.5 \%$ (vol/vol) penicillin (10, 000 unit), and 0.5\% (vol/vol) streptomycin (10, 000 unit). AML12 cells were cultured in DMEM: F12 medium supplemented with $10 \%$ fetal bovine serum, $10 \mu \mathrm{g} / \mathrm{mL}$ insulin, $5.5 \mu \mathrm{g} / \mathrm{mL}$ transferrin, $5 \mathrm{ng} / \mathrm{ml}$ selenium and $40 \mathrm{ng} / \mathrm{mL}$ dexamethasone. All cells were maintained at $37^{\circ} \mathrm{C}$ in a $5 \% \mathrm{CO}_{2}$ incubator.

Immunofluorescence. Cells were plated on confocal dishes (CellVis) and fixed in 4 wt\% paraformaldehyde for 15 min and permeabilized with $1 \% \mathrm{BSA}$ and $0.1 \%$ Tween 20 . Fixed cells were incubated in primary antibody at $4{ }^{\circ} \mathrm{C}$ overnight, washed three times for $5 \mathrm{~min}$ each, incubated in secondary antibody for $1 \mathrm{~h}$, then washed three times for $5 \mathrm{~min}$ each.

Western Blot. Total protein extracts were prepared in cell lysis buffer (Cell Signaling Technology, CATALOG \# 9803S) followed by 5 freeze-thaw circles. Protein concentration was determined by Coomassie Blue method. Protein extracts $(20 \mu \mathrm{g}$ per lane) were separated by SDS-PAGE and transferred to polyvinylidene difluoride (PVDF) membranes. Western blotting was performed according to standard protocols ${ }^{2}$. Gel analysis was conducted using ImageJ.

Determination of the Mitochondrial Membrane Potentials by Rhodamine 123. Cells were firstly incubated with Rhodamine 123 (10 $\mu \mathrm{g} / \mathrm{mL}$ ) for $1 \mathrm{~h}$. After $1 \mathrm{~h}$ of incubation, cells were washed by fresh medium for 5 times to remove the excess Rhodamine 123 . Then, cells were incubated in fresh culture medium for another $24 \mathrm{~h}$. Before the detection of intracellular Rhodamine 123, cells were detached from petri dishes (via trypsin) and washed 3 times by PBS. The cell suspensions were diluted into $10^{5}$ cells $/ \mathrm{mL}$. $1 \mathrm{~mL}$ cell suspension was added into cuvette. The fluorescence intensity of the intracellular Rhodamine 123 was then determined by Shimadzu RF-5301-PC fluorescence spectrophotometer. $\lambda_{\mathrm{ex}} \sim 504 \mathrm{~nm} ; \lambda_{\mathrm{em}} \sim 534 \mathrm{~nm}$. PBS was used as the blank control.

Determination of the Drug Loading Efficiency (LE\%) and Encapsulation Capacity (EC). To facilitate the detection of CLRP, we connected NBD to the molecule (CLRPs-NBD). A mixture of CLRPs-NBD $(100 \mu \mathrm{M})$ and Flag- $(\mathrm{C} 16)_{2}(50 \mu \mathrm{M})$ were prepared. The mixture was incubated at room temperature for more than two hours for equilibrium. High-speed centrifuge $(12,000 \mathrm{Xg}, 1 \mathrm{~h})$ was applied to spin down the Flag- $(\mathrm{C} 16)_{2}$ nanoparticles encapsulating CLRPs-NBD (Figure S23). Free CLRPs-NBD was unable to precipitate (Figure S23). The CLRPs-NBD concentrations in the supernatant before and after the centrifuge were determined by fluorometer according to a standard curve (Figure S21). The LE\% was determined by ([CLRPs-NBD $\left.]_{0}-[C L R P s-N B D]_{t}\right) /[C L R P s-N B D]_{0} X 100 \%$, where $[C L R P s-N B D]_{0}$ and [CLRPs-NBD $]_{t}$ are the concentration of CLRPs-NBD in the supernatant before and after centrifuge. With the result of LE\%, the EC can be determined. EC is defined by the mass $(\mu \mathrm{g})$ of CLRP in per mg Flag- $(\mathrm{C} 16)_{2}$ nanoparticles.

Quantification of Whole Cell ATP. The ATP assay kit was purchased from Abcam (ab83355). The quantification of whole cell ATP was performed according to the manufacture's protocol.

Multidrug Resistance (MDR) Assay. The MDR assay kit was purchased from Abcam (ab112142). The evaluation of MDR after the treatment of PBS, Flag- $(\mathrm{C} 16)_{2}, \mathrm{CLRP}$ and the mixture of CLRP and Flag- $(\mathrm{C} 16)_{2}$ was performed according to the manufacture's protocol.

Imaging ATP in cells. The ATP probe (ATP-Red) was purchased from Sigma-Aldrich (SCT045). The visualization of ATP in cells was performed following the manufacture's protocol. Zeiss 880 confocal fluorescence microscope was used for imaging.

Statistical analysis: Data presented are means \pm SD. Significance levels are calculated using t-test analysis. The ANOVA for multiple comparisons is done via single-factor ANOVA analysis ${ }^{1}(\alpha=0.05)$. Results show that the " $F$ value" is always larger than the " $F$ critical value" when we are comparing the data collected from the groups treated by "Flag-(C16 $)_{2}$ + CLRP" to the data collected from the groups treated by PBS, free CLRP and Flag- $(\mathrm{C} 16)_{2}$ alone, respectively. This confirms that the data collected from the groups treated by "Flag$(\mathrm{C} 16)_{2}+\mathrm{CLRP} "$ is significantly different from the one collected from the groups treated by PBS, free CLRP and Flag-(C16) $)_{2}$ alone. All tests were analyzed from $n>3$ independent experiments per condition. 


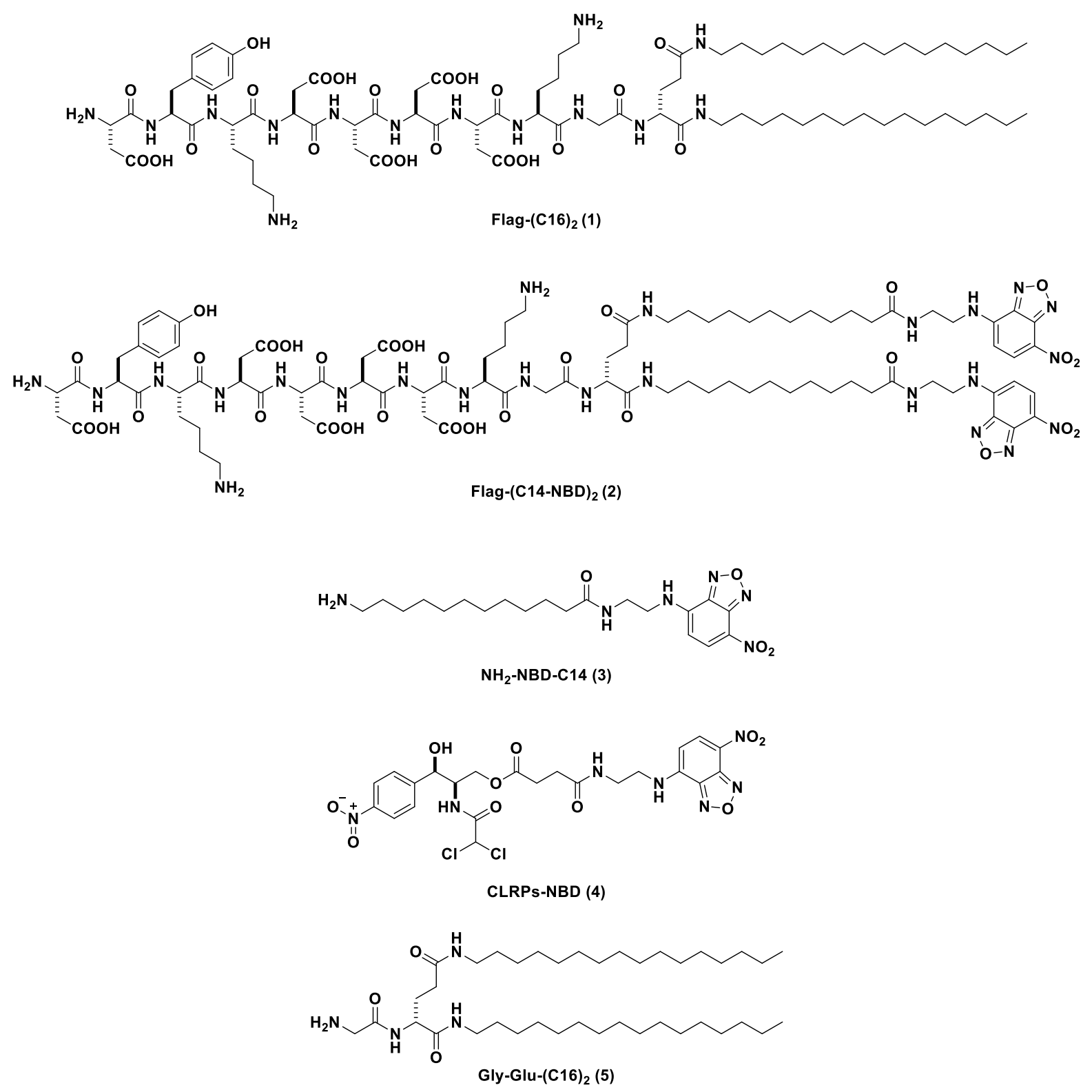

Scheme S1. The molecular structures of Flag-(C16) $)_{2}(\mathbf{1})$, Flag-(C14-NBD) $)_{2}(2), \mathrm{NH}_{2}-\mathrm{C} 14-\mathrm{NBD}(\mathbf{3}), \mathrm{CLRPs}-\mathrm{NBD}(\mathbf{4})$, and Gly-Glu-(C16) 2 (5). 

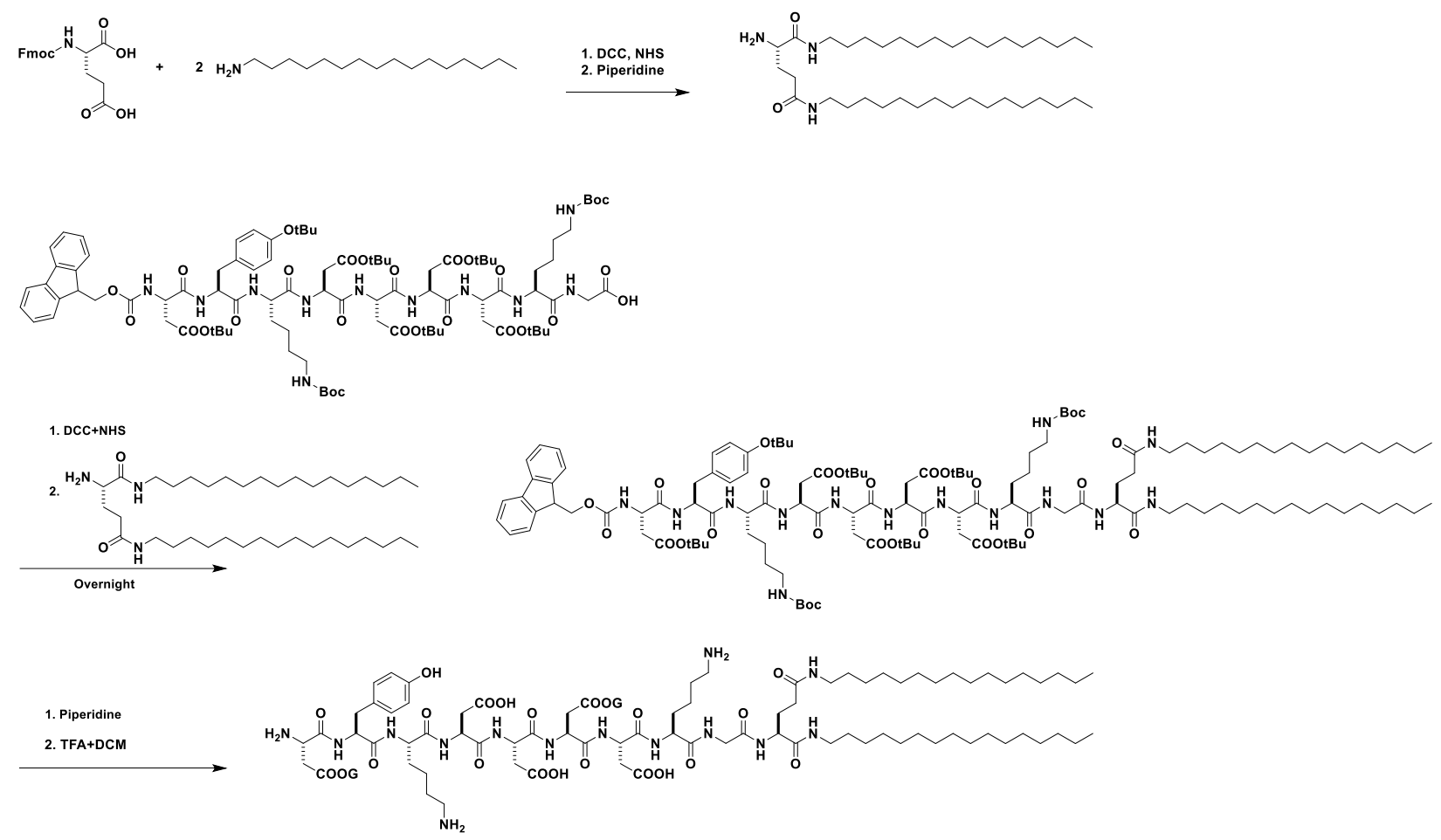

Scheme S2. The synthetic route of Flag- $(\mathrm{C} 16)_{2}(\mathbf{1})$.

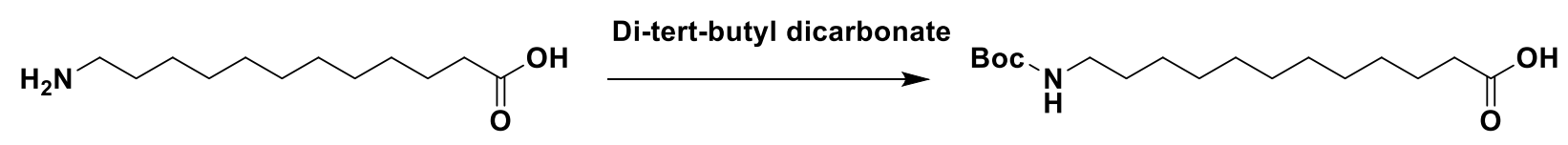

\section{1. $\mathrm{DCC}+\mathrm{NHS}$}
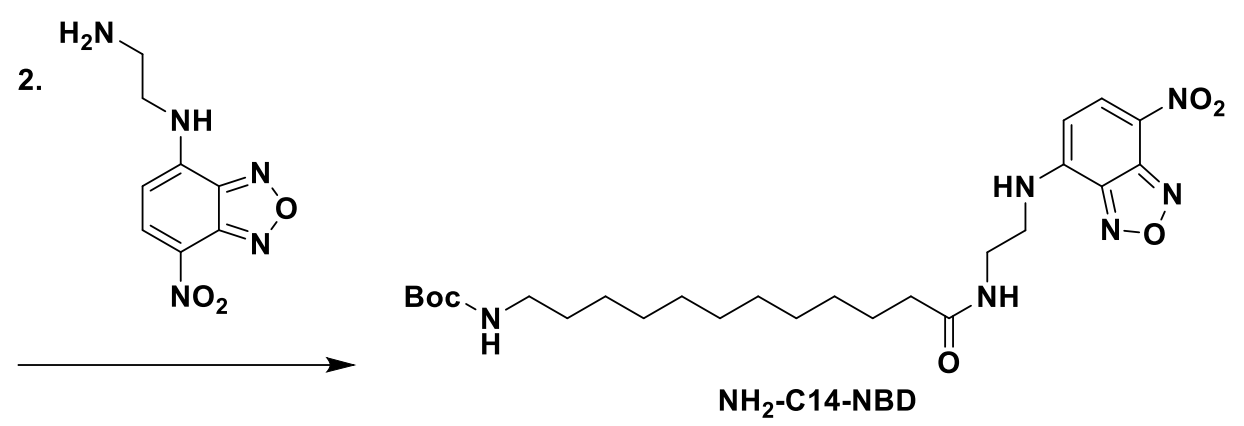

Scheme S3. The synthetic route of $\mathrm{NH}_{2}-\mathrm{C} 14-\mathrm{NBD}$ (4). 

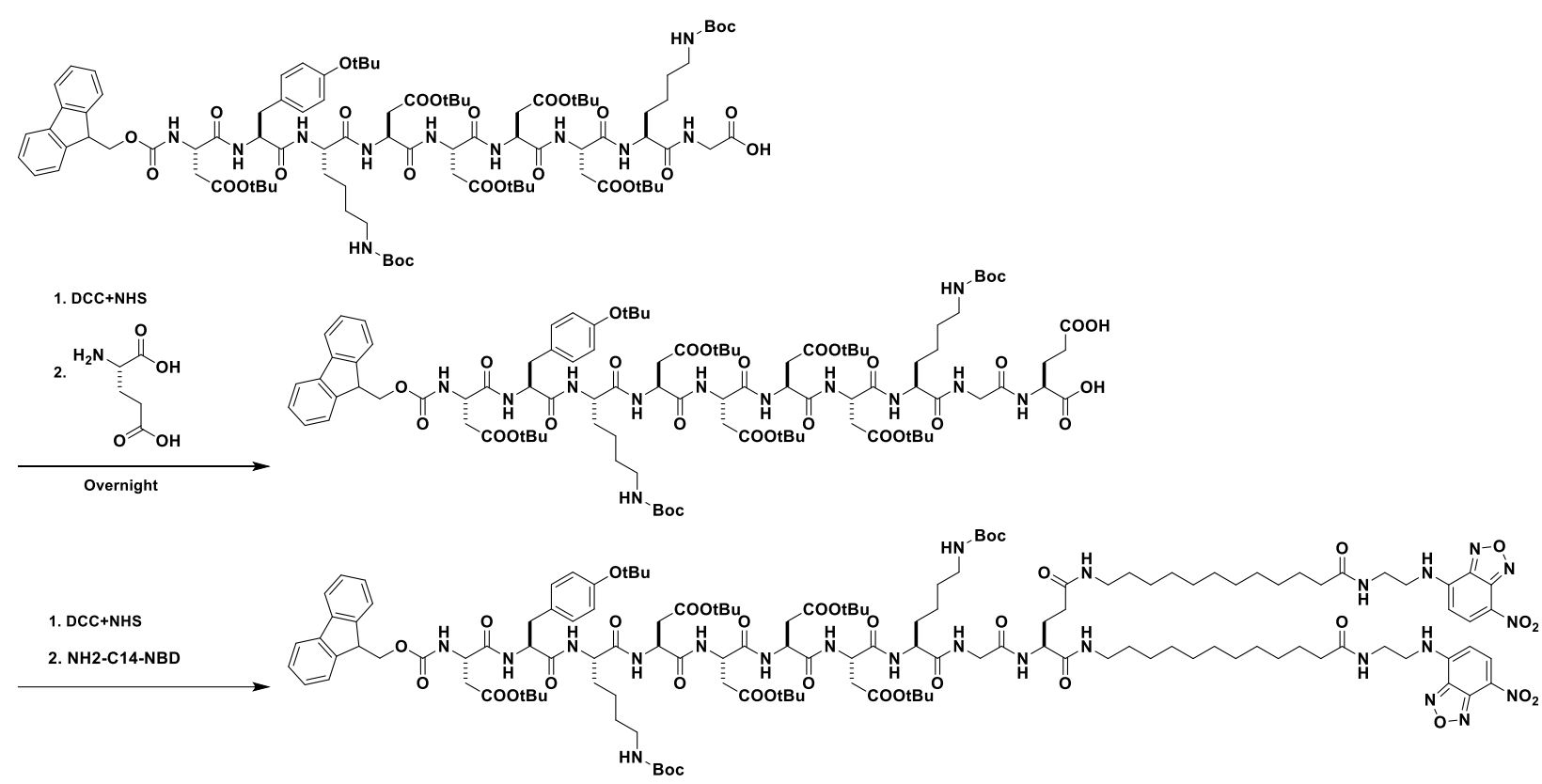

1. Piperidine

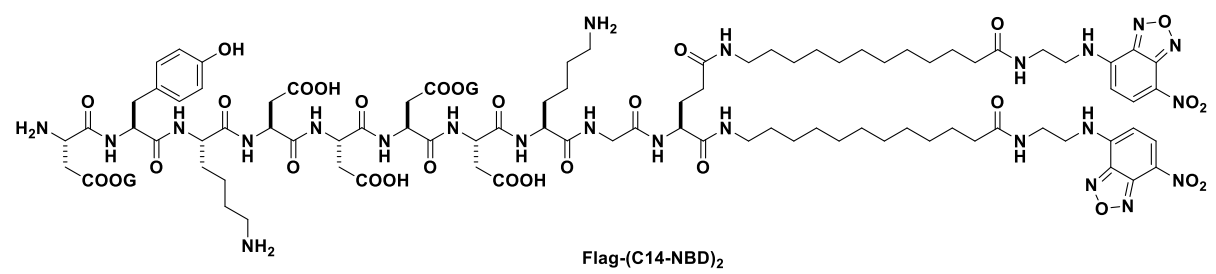

Scheme S4. The synthetic route of Flag-(C14-NBD) 2 (2). 
A

HeLa cell

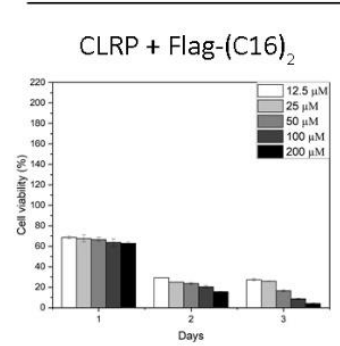

${ }^{2}$
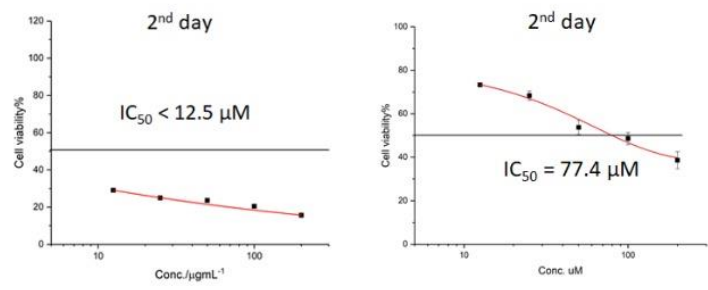

B

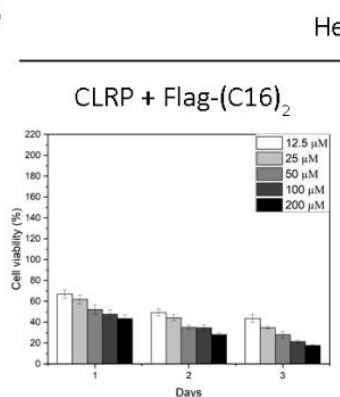

HepG2 cell
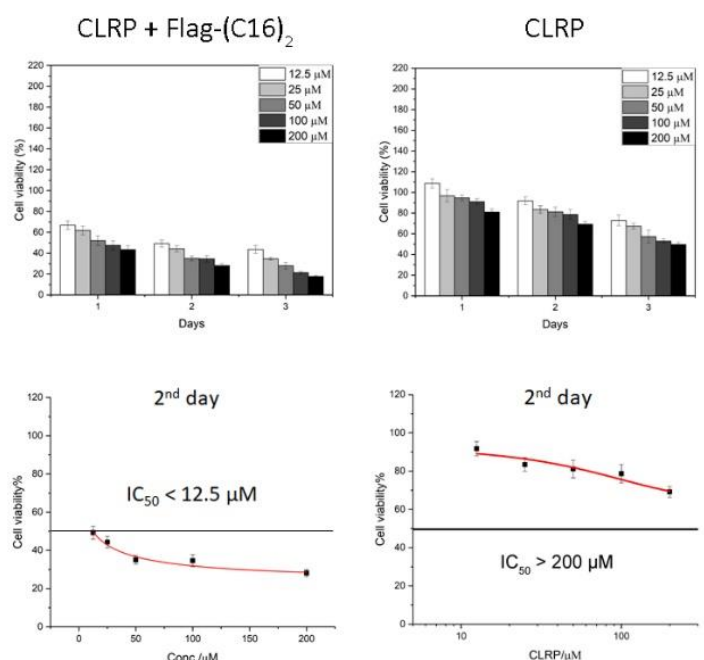

C

HS-5 cell
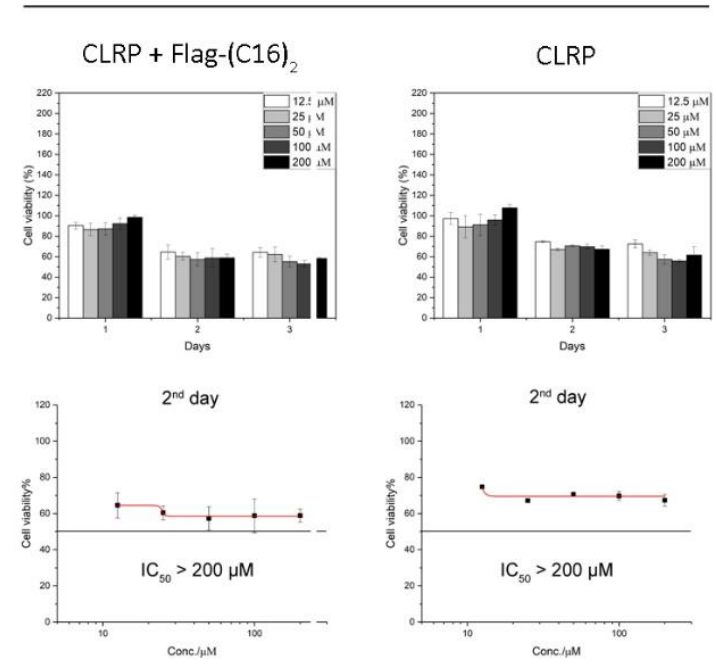

D
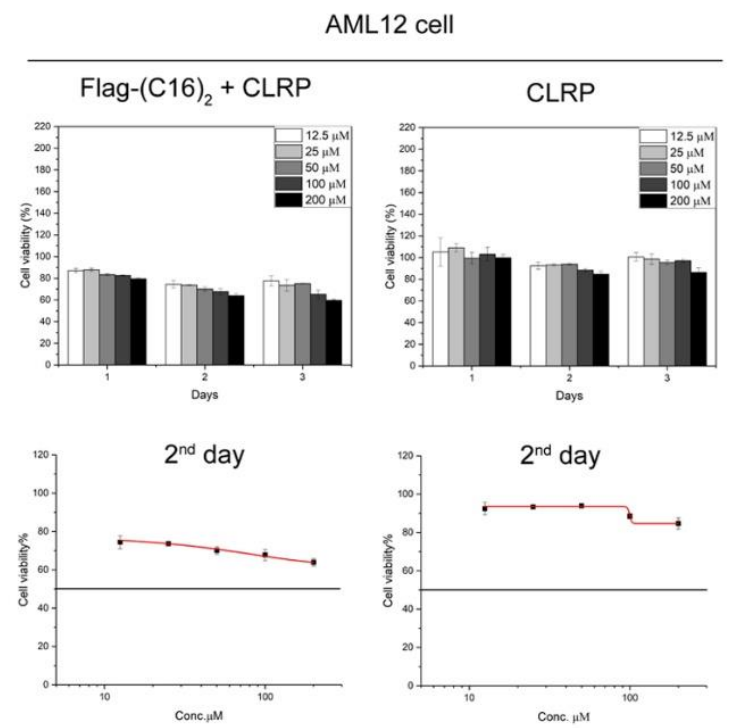

Figure S1. Combining CLRP with Flag- $(\mathrm{C} 16)_{2}(25 \mu \mathrm{M})$ increases the cancer suppression efficacy. $(\mathrm{A}, \mathrm{B})$ Cytotoxicity of CLRP and CLRP + Flag-(C16) 2 and CLRP + Flag-(C14-NBD) 2 against cancer cells, (A) HeLa and (B) HepG2 cells. (C, D) Cytotoxicity of CLRP and CLRP + Flag-(C16) 2 against noncancerous cells, (C) HS5 and (D) AML12 cells. 
A

HepG2 cell

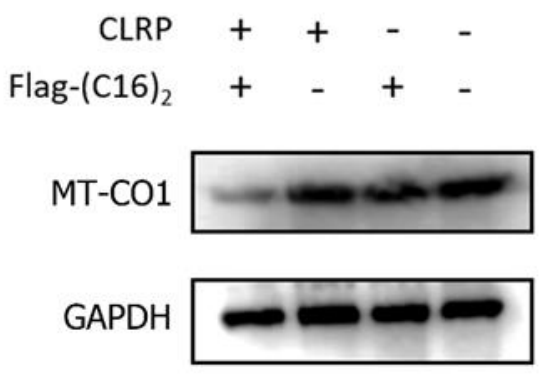

Trial 2

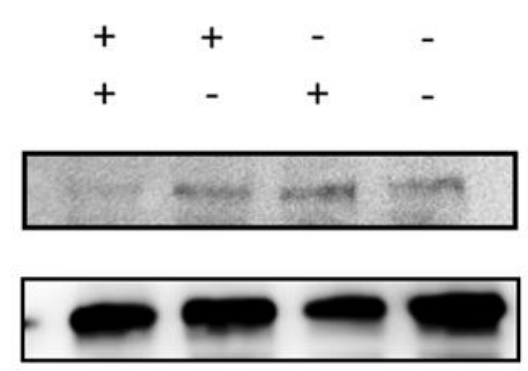

Trial 3

\section{B}

Anti-MT-CO1

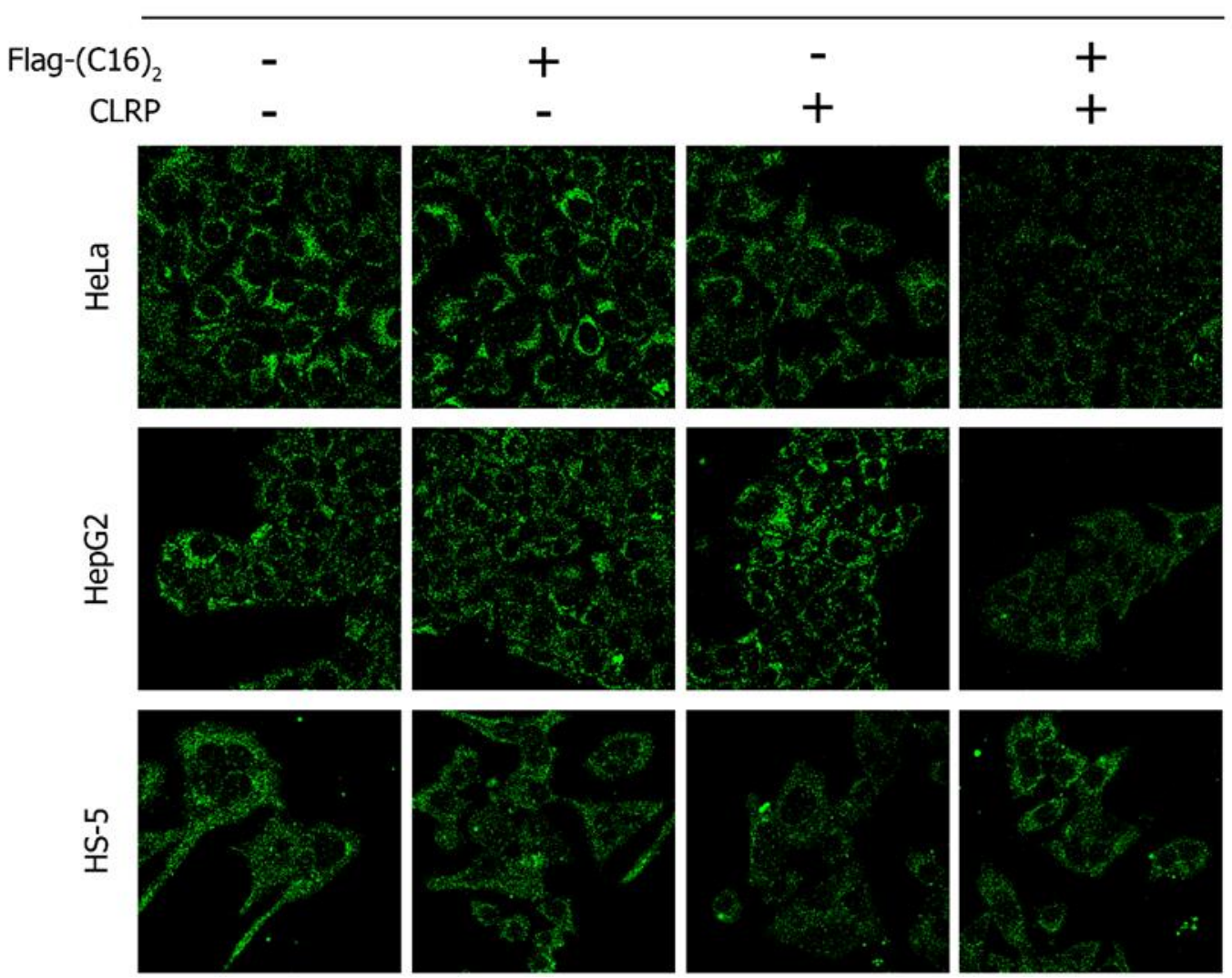

Figure S2. Determination of MT-COX-1 in HeLa, HepG2, and HS-5 cells treated by solvent control (PBS), Flag-(C16)2, plain CLRP, and the mixture of CLRP and Flag-(C16)2. (A) Western blot analysis and (B) immunofluorescence staining of MT-COX-1 in cells treated by conduction of interest. 
A HeLa HepG2 HS-5

HeLa HepG2 HS-5
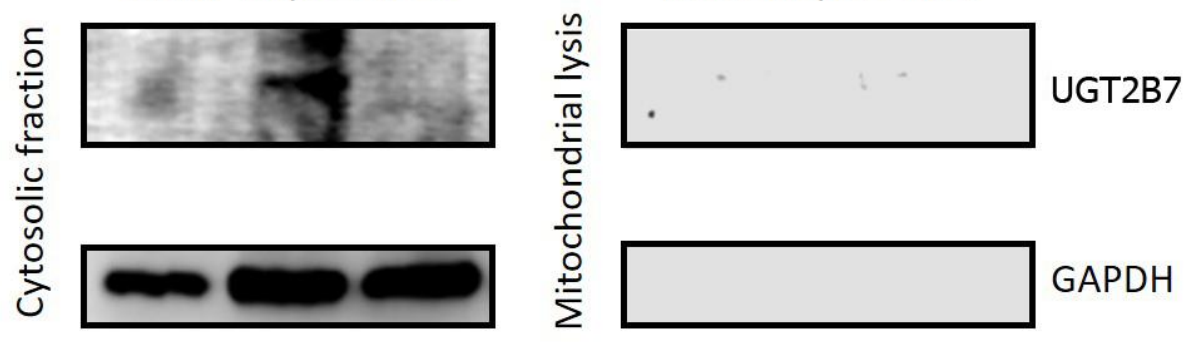

B
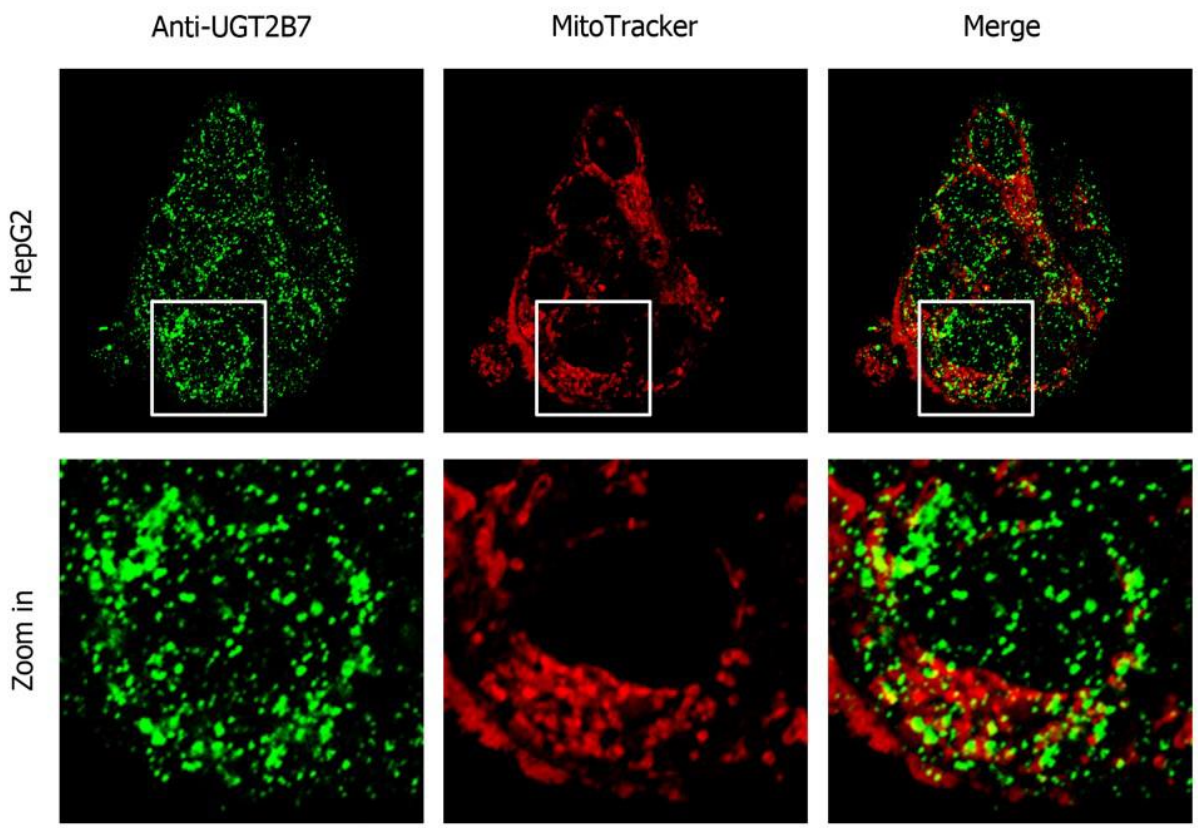

C
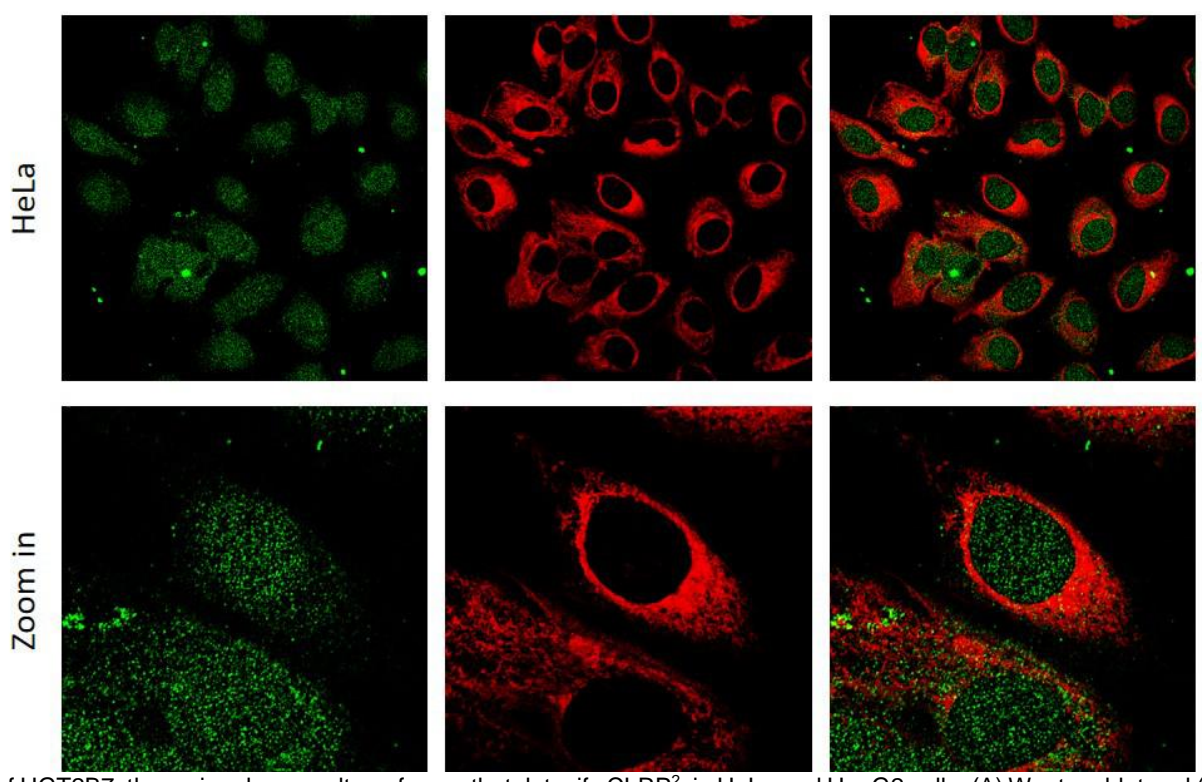

Figure S3. Determination of UGT2B7, the major glucuronyltransferase that detoxify CLRP2, in HeLa and HepG2 cells. (A) Western blot and (B) immunofluorescence staining of UGT2B7 in HeLa and HepG2 cells. 


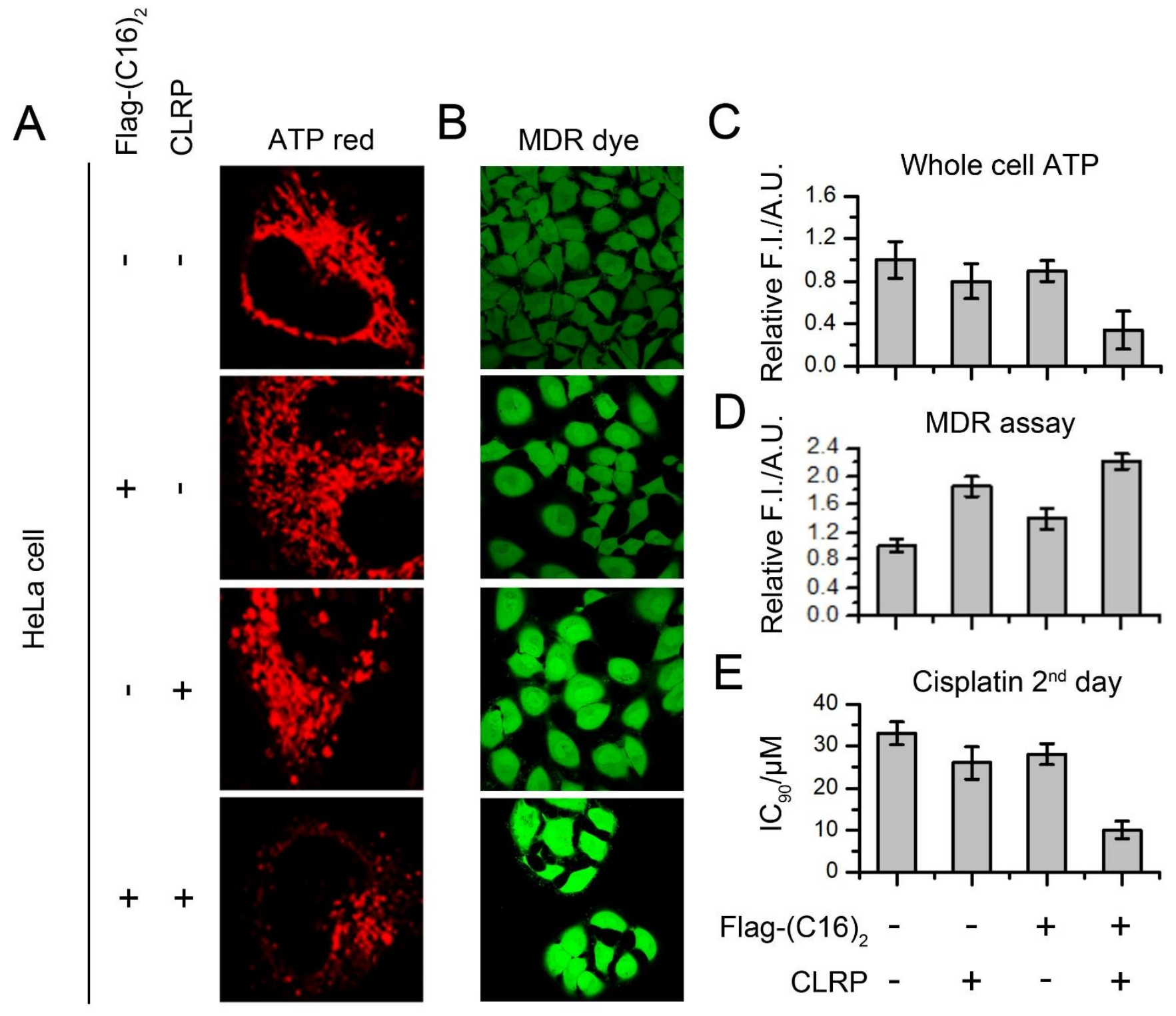

Figure S4. Combining Flag- $(\mathrm{C} 16)_{2}$ and CLRP inhibit OXPHOS and Multidrug resistance (MDR) on HeLa cells. (A) Visualization of ATP (red) in HeLa cells pretreated by solvent control (PBS), Flag- $(\mathrm{C} 16)_{2}(50 \mu \mathrm{M}, 24 \mathrm{~h})$, free CLRP $(50 \mu \mathrm{M}, 24 \mathrm{~h})$ and the mixture of CLRP $(50 \mu \mathrm{M})$ and Flag-(C16) 2 (50 $\left.\mu \mathrm{M}, 24 \mathrm{~h}\right)$. (B) Fluorescence images of MDR assay in HeLa cells pretreated by solvent control (PBS), Flag-(C16) $2(25 \mu \mathrm{M}, 24 \mathrm{~h})$, free CLRP $(50 \mu \mathrm{M}, 24 \mathrm{~h})$ and the mixture of CLRP (50 $\mu \mathrm{M})$ and Flag- $(\mathrm{C} 16)_{2}(25 \mu \mathrm{M}, 24 \mathrm{~h})$. The higher fluorescence intensity, the more inhibition on MDR. (C) Relative whole cell ATP level in HeLa cells treated by the condition in (A). (D) MDR assay in HeLa cells treated by the condition in (B). (E) The $2^{\text {nd }}$ day IC 90 of Cisplatin for HeLa pretreated by solvent control (PBS), Flag-(C16) 2 (25 $\mu \mathrm{M}, 24 \mathrm{~h})$, free CLRP $(50 \mu \mathrm{M}, 24 \mathrm{~h})$ and the mixture of CLRP $(50 \mu \mathrm{M})$ and Flag- $(\mathrm{C} 16)_{2}(25 \mu \mathrm{M}, 24 \mathrm{~h})$. Flag-(C16) 2 and CLRP were removed after the pretreatment, immediately followed by adding Cisplatin. 
A

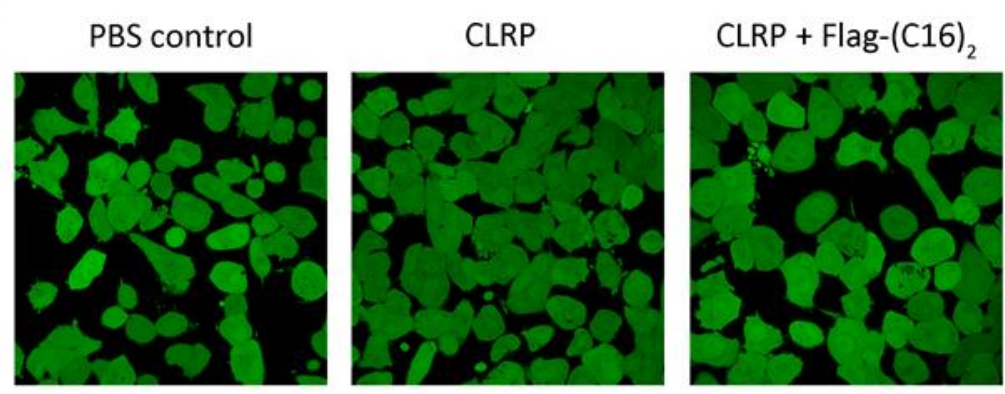

B

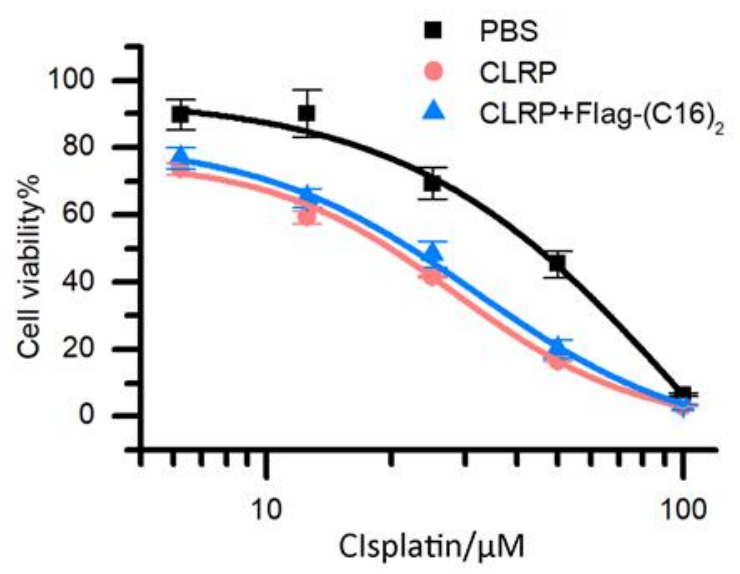

Figure S5. Combining Flag-(C16)2 and CLRP hardly inhibits multidrug resistance (MDR) in HS-5 cells. (A) Fluorescence images of MDR assay in HS-5 cells pretreated by solvent control (PBS), free CLRP $(50 \mu \mathrm{M}, 24 \mathrm{~h})$ and the mixture of CLRP $(50 \mu \mathrm{M})$ and Flag-(C16)2 $(25 \mu \mathrm{M}, 24 \mathrm{~h})$. The higher fluorescence intensity, the more inhibition on MDR. (B) The $2^{\text {nd }}$ day cell viability of HS-5 incubated with cisplatin after the pretreatment by solvent control (PBS), free CLRP ( $50 \mu M, 24 \mathrm{~h}$ ) and the mixture of CLRP $(50 \mu \mathrm{M})$ and Flag- $(\mathrm{C} 16)_{2}(25 \mu \mathrm{M}, 24 \mathrm{~h})$. Flag-(C16) $)_{2}$ and CLRP were removed after the pretreatment, immediately followed by adding Cisplatin.
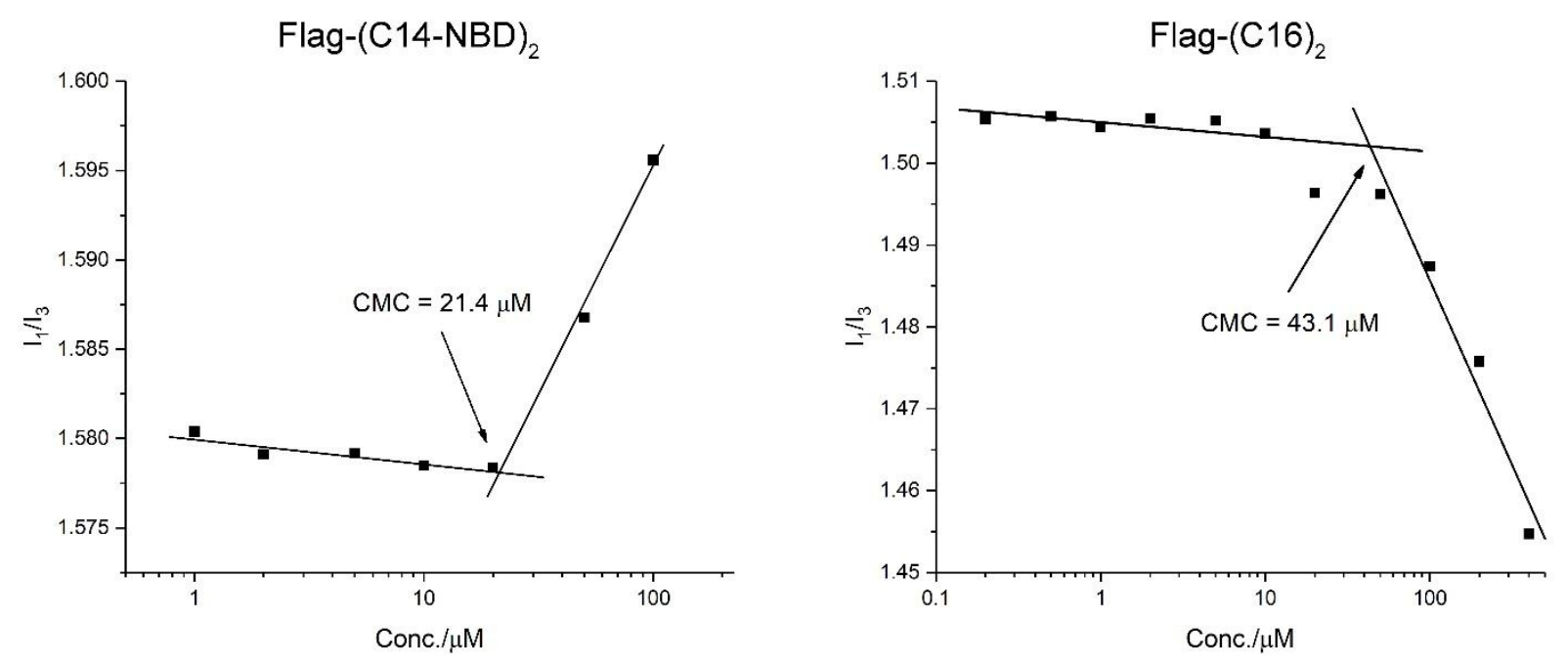

Figure S6. The critical micelle concentrations (CMCs, in PBS) of Flag-(C16)2 and Flag-(C14-NBD)2. 
A

$50 \mu \mathrm{M}$ Flag-(C16)

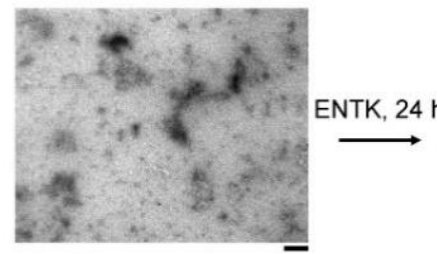

B

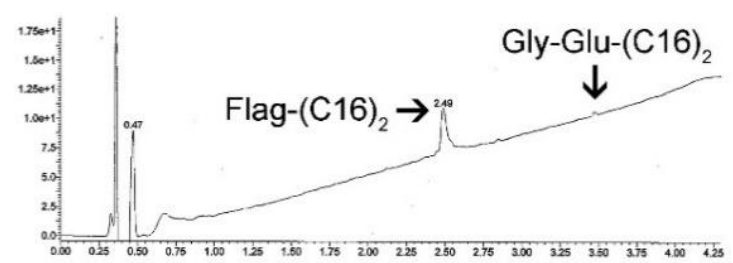

C

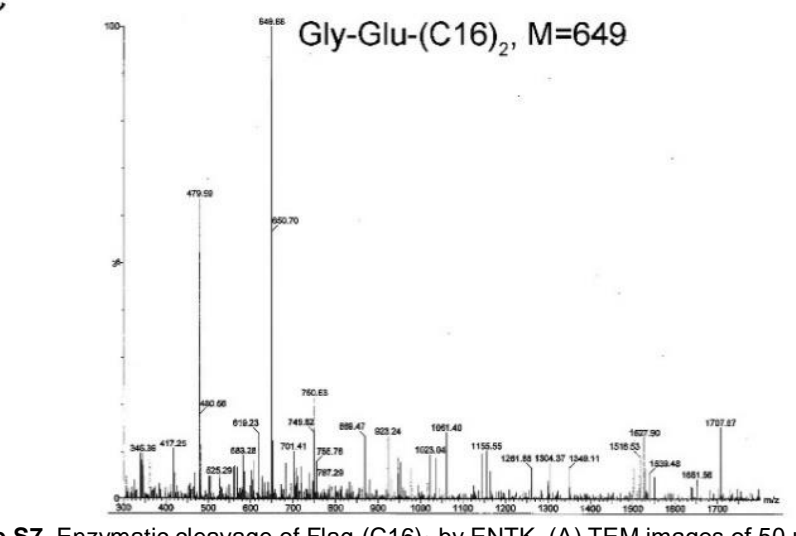

Flag- $(\mathrm{C} 16)_{2}+\mathrm{NH}_{2}-(\mathrm{C} 16)_{2}$

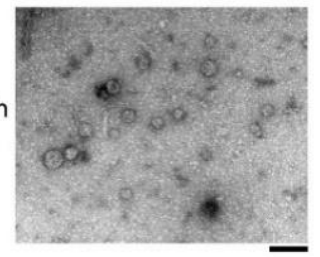

C

D

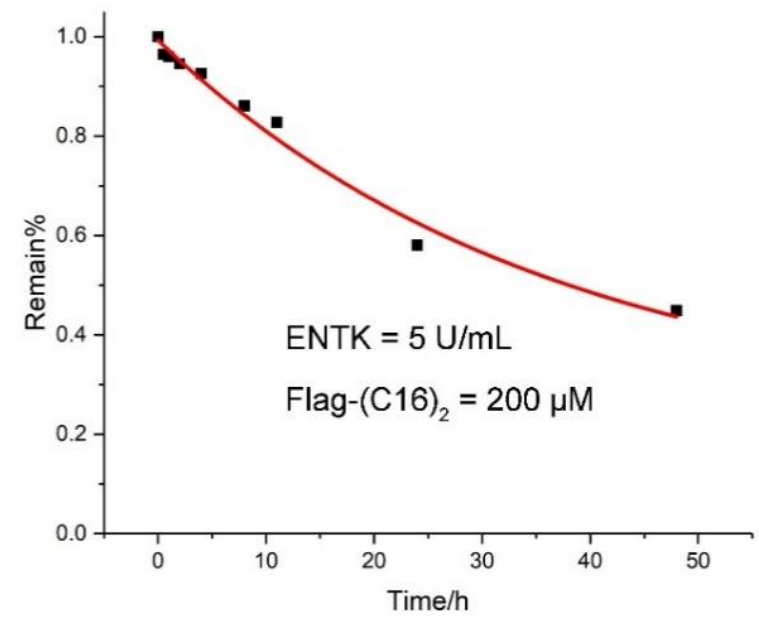

Figure S7. Enzymatic cleavage of Flag-(C16) $)_{2}$ by ENTK. (A) TEM images of $50 \mu \mathrm{M}$ Flag-(C16) $)_{2}$ before and after adding ENTK (10 U/mL, $\left.24 \mathrm{~h}\right)$. (B) HPLC analysis of Flag-(C16) $)_{2}$ after adding ENTK (10 U/mL, $24 \mathrm{~h}$ ). (C) Mass spectrum of the enzymatic product Gly-Glu-(C16)2. (D) Conversion rate of Flag-(C16) 2 by ENTK (5 $\mathrm{U} / \mathrm{mL})$. 

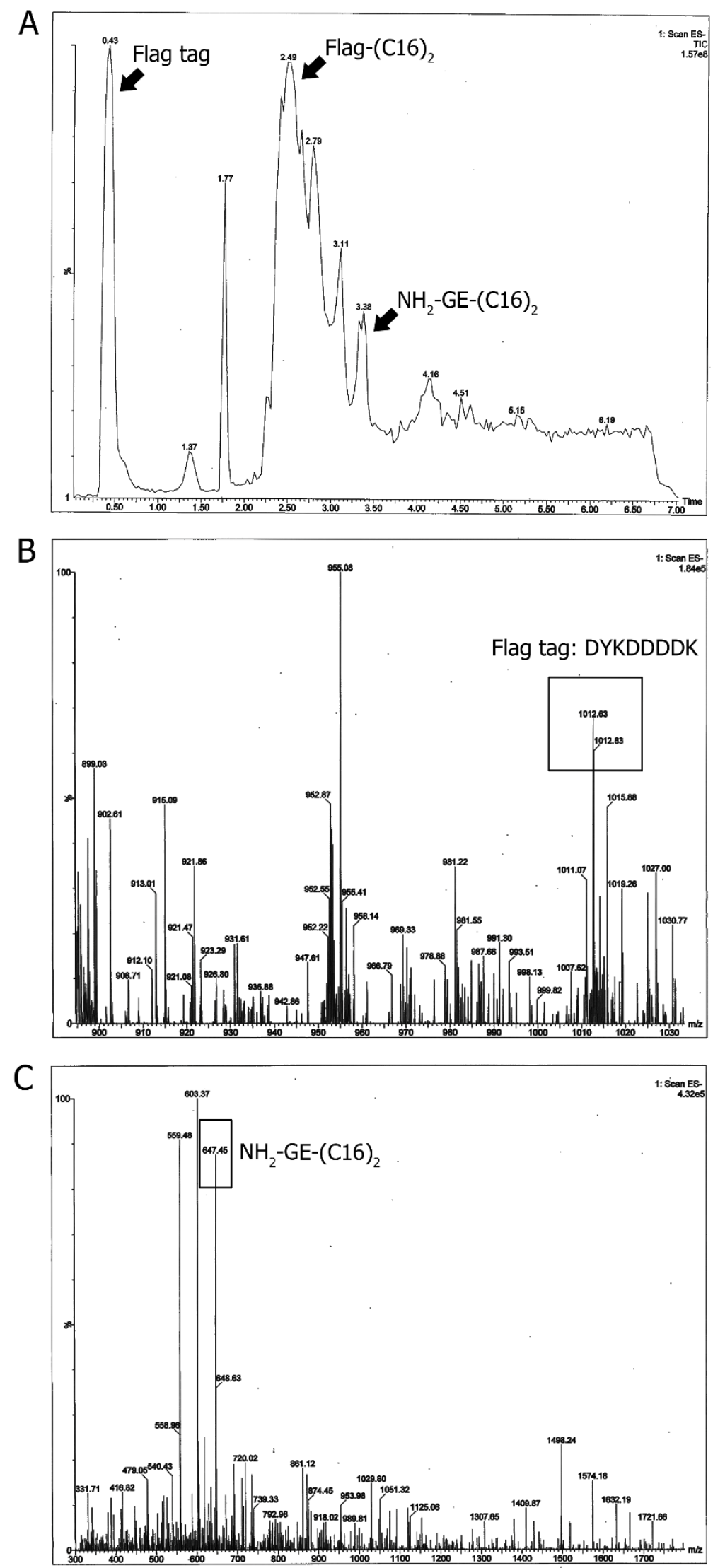

Figure S8. Enzymatic cleavage of Flag-(C16) $)_{2}$ in HepG2 cell lysis. (A) LC-MS analysis of Flag-(C16) $)_{2}$ incubated in HepG2 cell lysis for 24 h. (B) and (C) Mass spectra of Flag-tag (B) and $\mathrm{NH}_{2}-\mathrm{GE}-(\mathrm{C} 16)_{2}(\mathrm{C})$ found in the cell lysis. 
HS-5 + Flag-(C14-NBD)

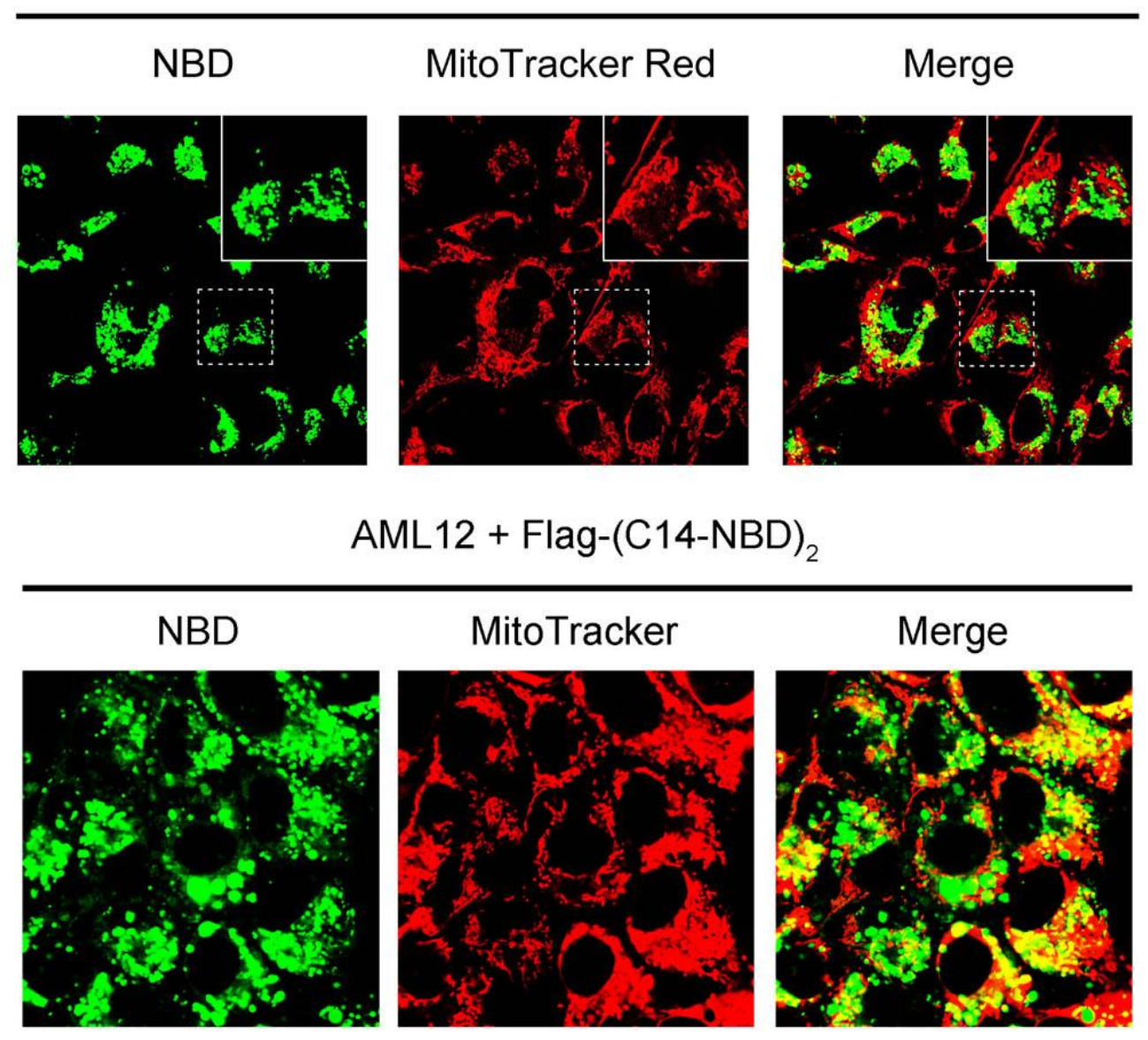

Figure S9. The fluorescent images of HS-5 and AML12 cells incubated with Flag-(C14-NBD) $2(50 \mu M, 2$ h). 
HepG2 + CLRPs-NBD
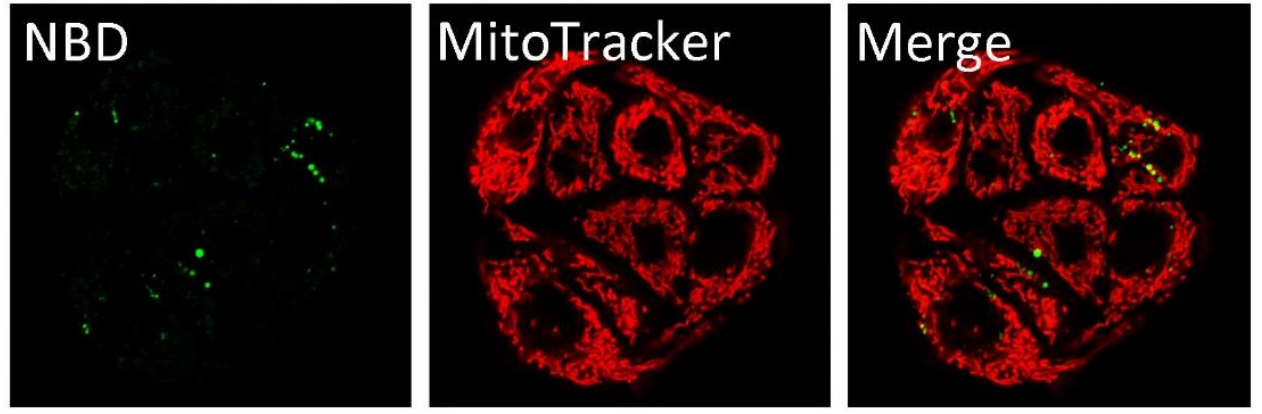

HeLa + CLRPs-NBD

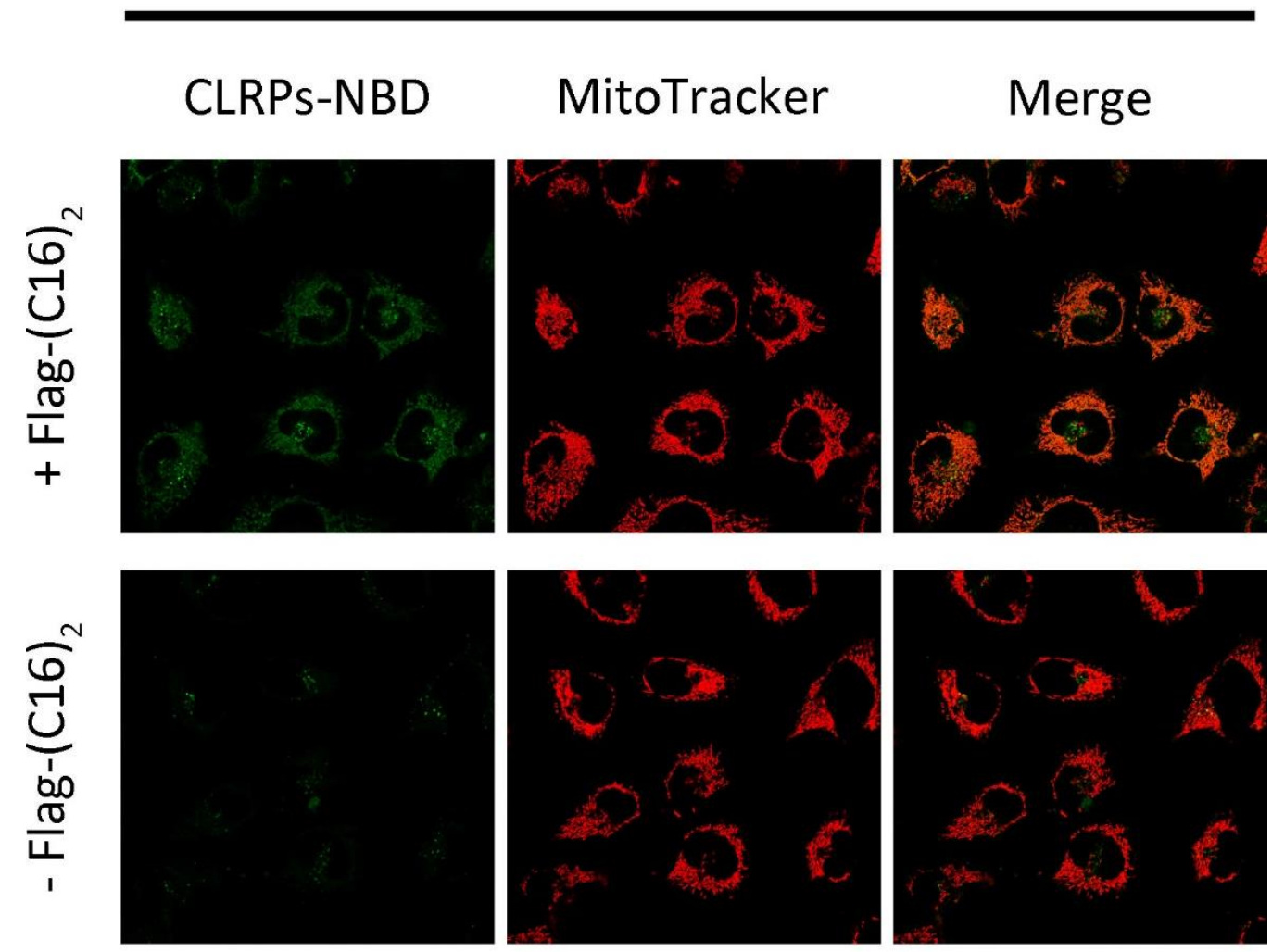

Figure S10. The fluorescent images of HepG2 and HeLa cells incubated with $100 \mu \mathrm{M} \mathrm{CLRPs-NBD}$ in the presence/absence of $50 \mu \mathrm{M}$ Flag-(C16) $)_{2}$ for $8 \mathrm{~h}$

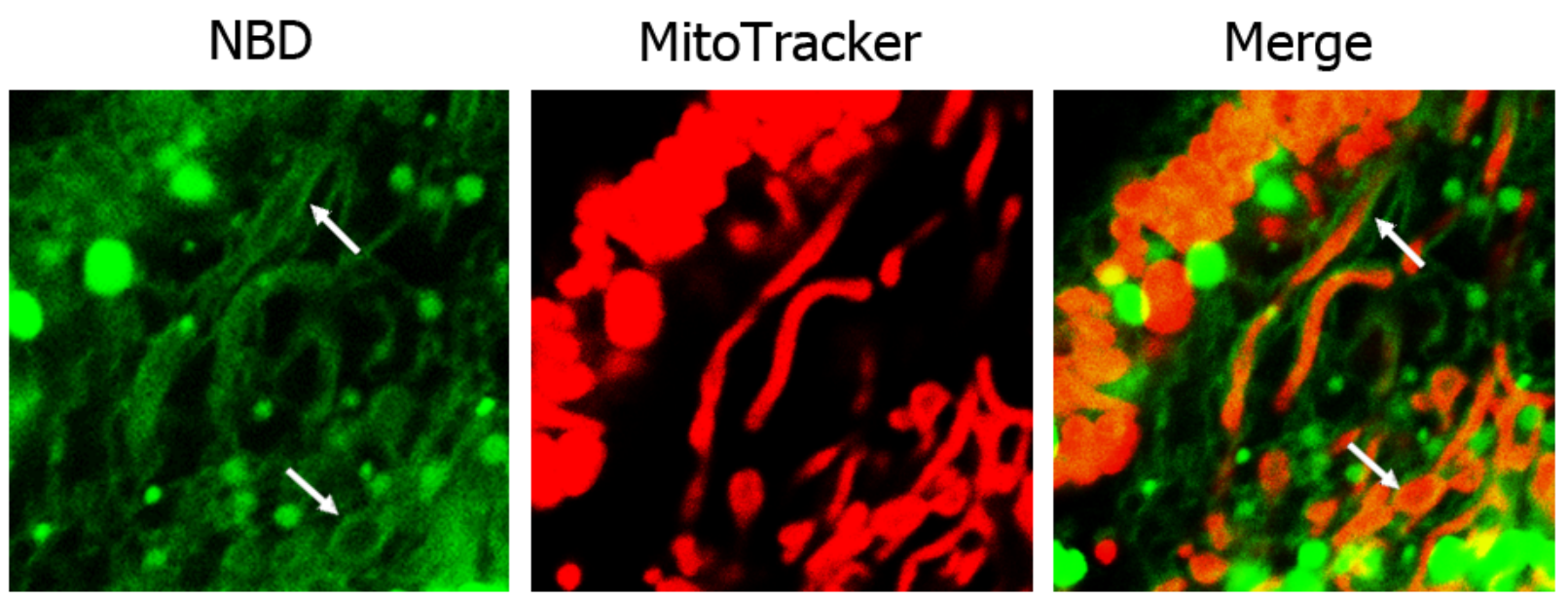


Figure S11. The high resolution confocal fluorescent images of HepG2 cells incubated with Flag-(C14-NBD) 2 . The mitochondrial outer membrane exhibits green fluorescence (indicated by arrows) from NBD.

\section{HeLa + Flag-(C14-NBD)}

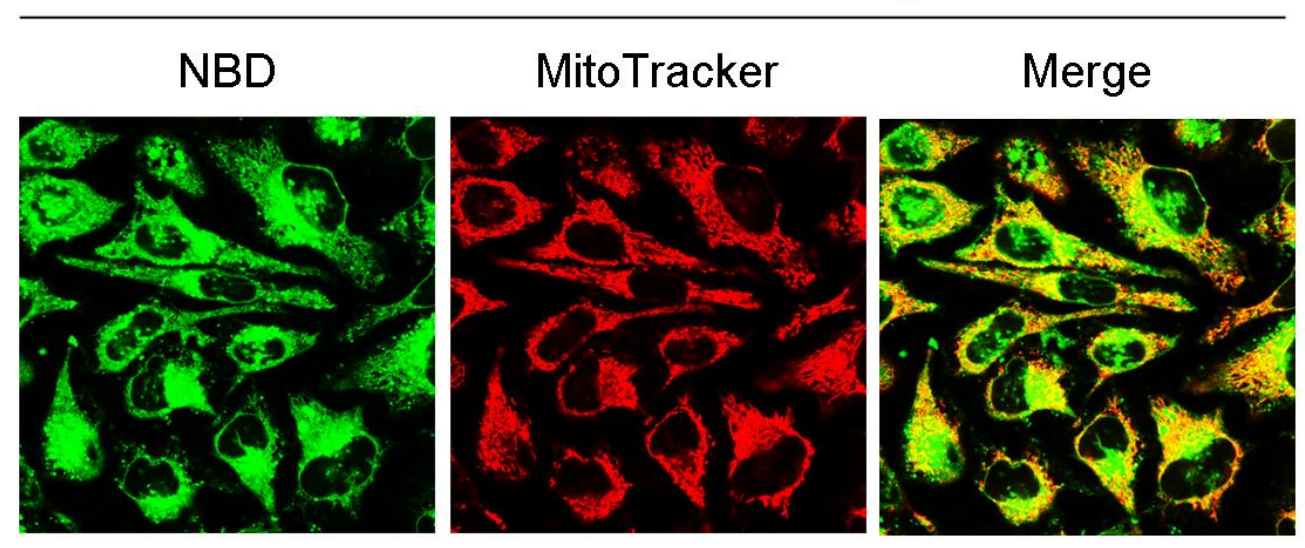

Figure S12. The fluorescent images of HeLa cells incubated with Flag-(C14-NBD) $2(50 \mu \mathrm{M}, 2 \mathrm{~h})$.
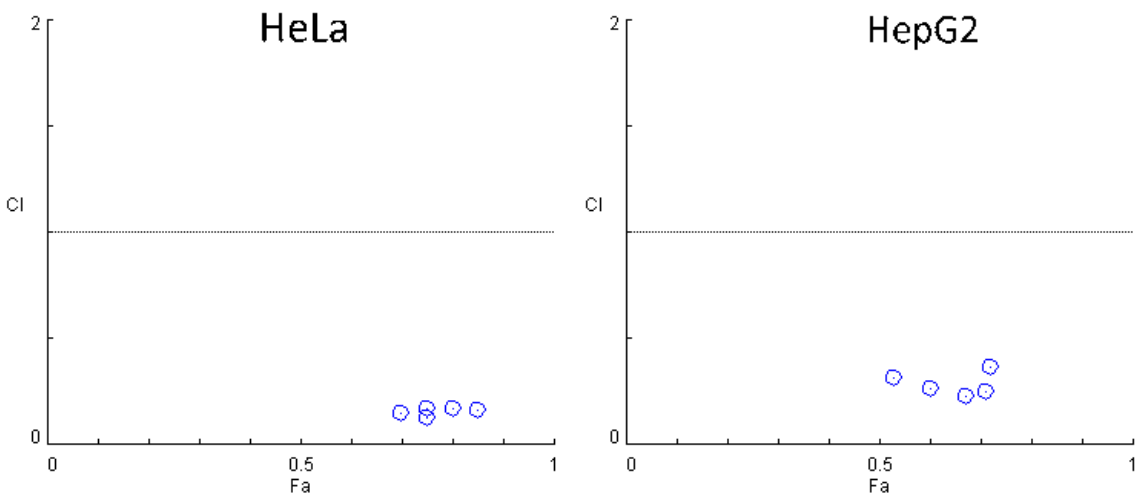

Figure S13. Synergistic effects of the combination of Flag-(C16) $2(25 \mu \mathrm{M})$ and CLRP $(200,100,50,25$ and $12.5 \mu \mathrm{M})$ on the inhibition of HeLa and HepG2 cells calculated by CompuSyn. $\mathrm{Cl}<1$ indicates synergism.

HeLa Flag-(C16) $48 \mathrm{~h}$

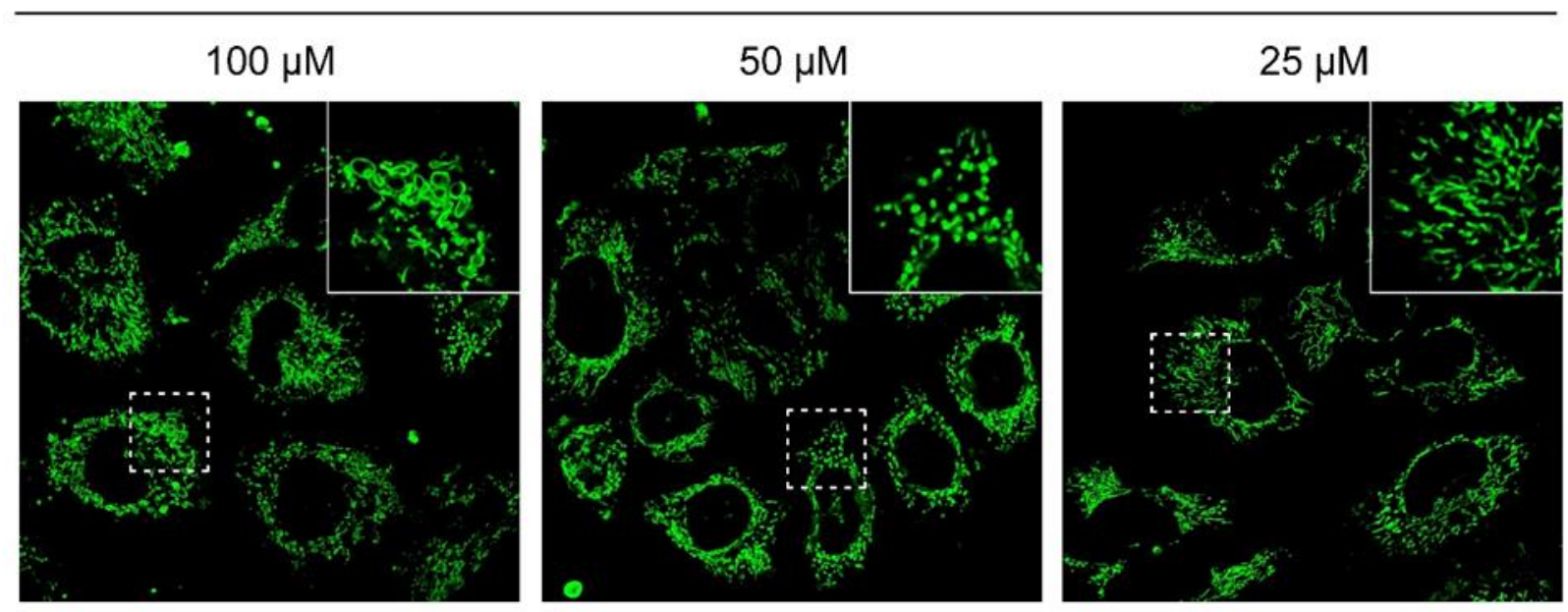

Green = MitoTracker

Figure S14. Flag-(C16) 2 induced mitochondria fragmentation in HeLa cells. 
HeLa Flag-(C16) $)_{2} 48 \mathrm{~h}$

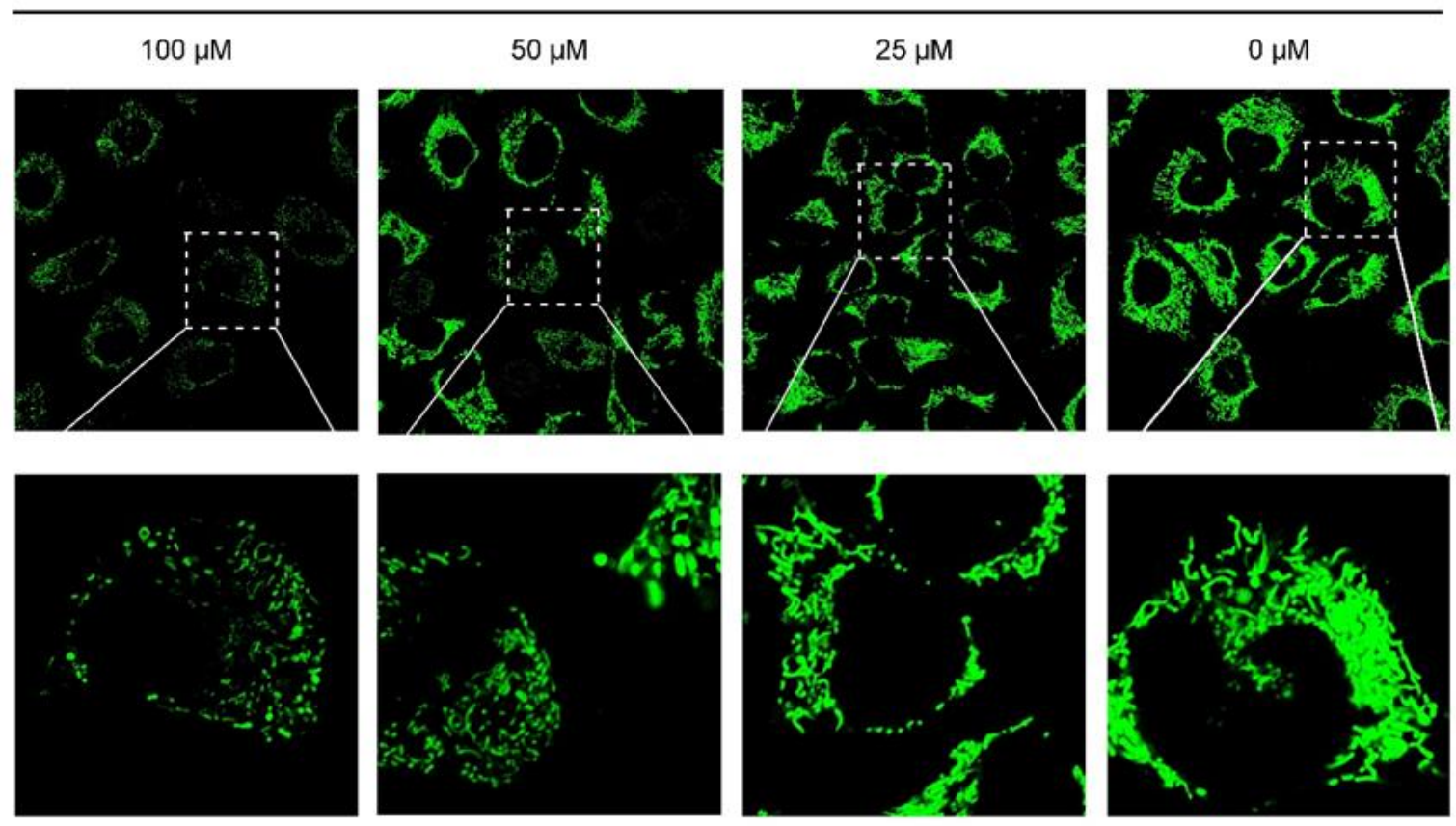

Green $=$ Rhodamine 123

Figure S15. Flag-(C16) 2 induced mitochondria depolarization in HeLa cells after $48 \mathrm{~h}$ incubation.

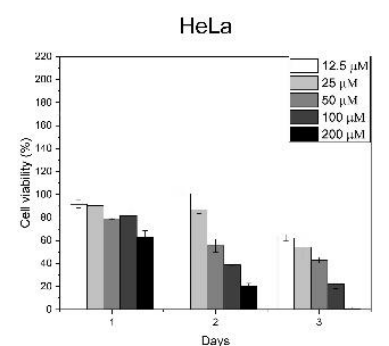

2nd day

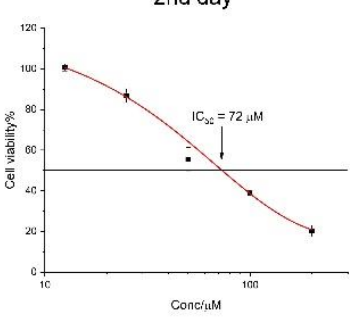

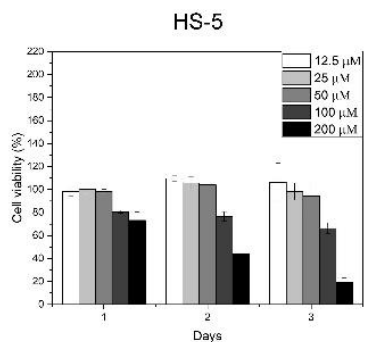

Days

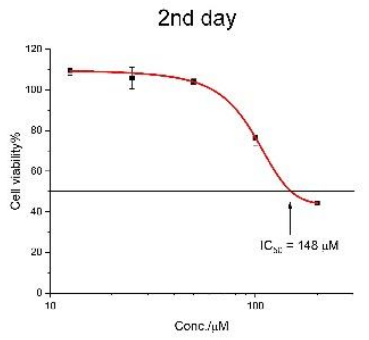

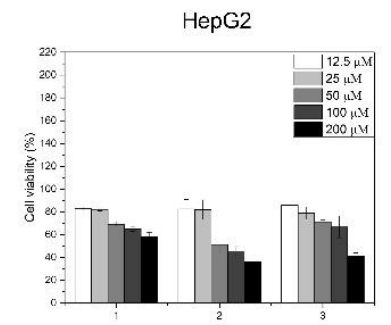

Days

2nd day

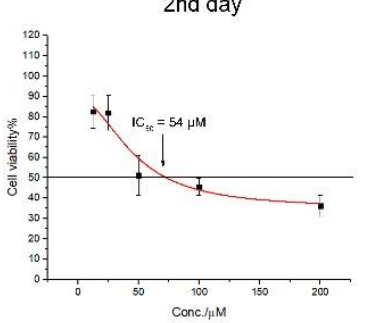

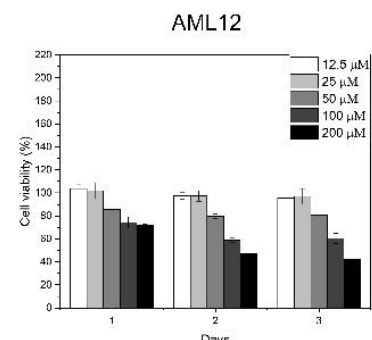

Days

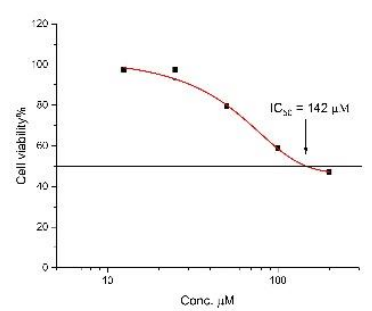

Figure S16. The cytotoxicity of Flag-(C16) 2 against HeLa, HepG2, HS-5, and AML12 cells. 
HeLa Flag-(C16) $48 \mathrm{~h}$

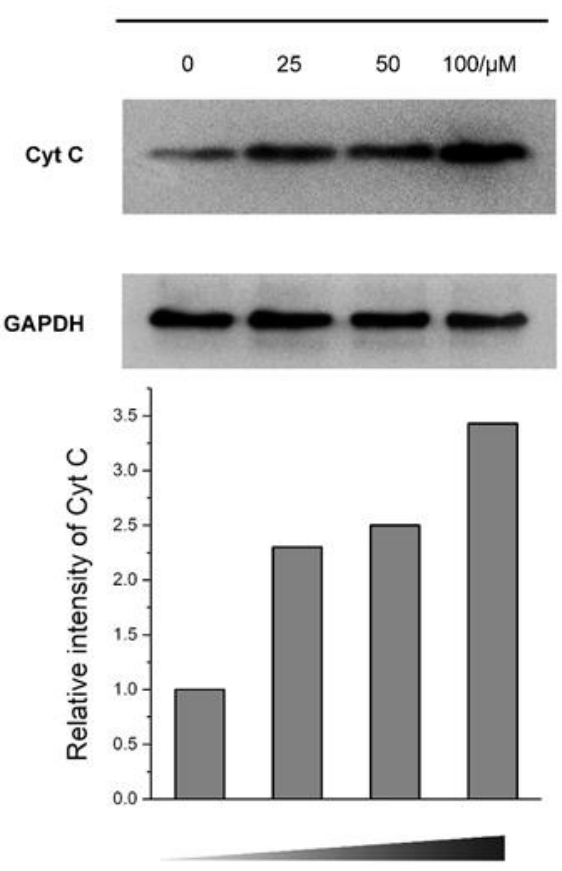

Figure S17. Flag- $(C 16)_{2}$ induced the release of Cyt $C$ from mitochondria of HeLa cells after 48 h incubation. 
A

(D) Flag-(C14-NBD) ${ }_{2}$

MitoTracker

Merge
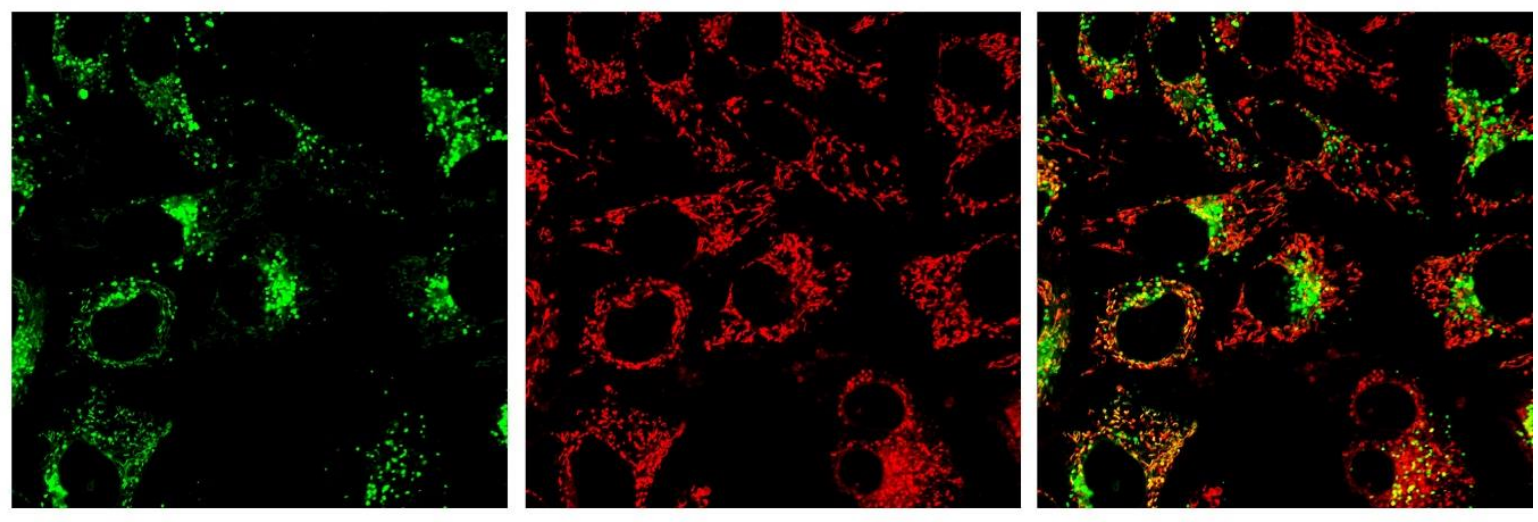

B

HeLa CLRP + (D) Flag-(C16) 2 2nd day

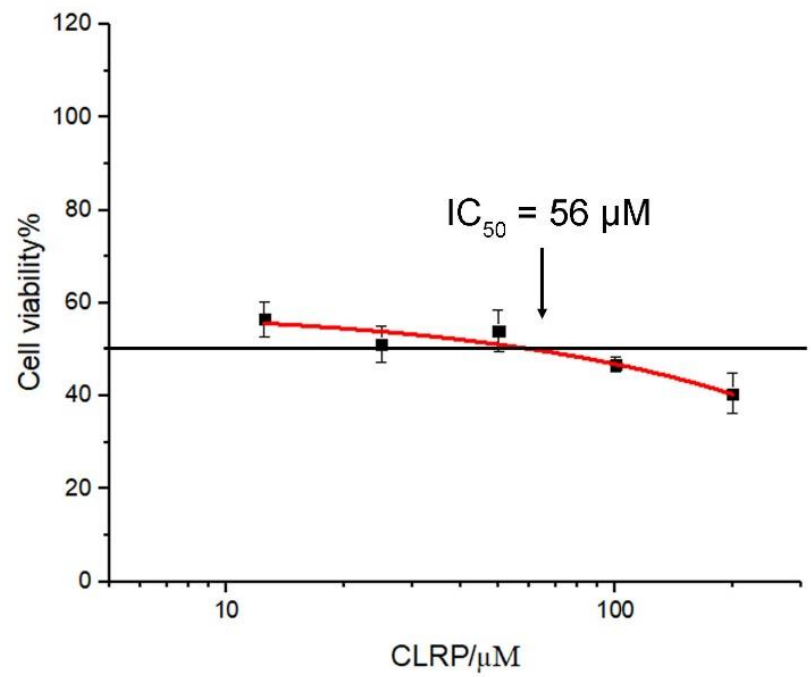

Figure S18. The D-enantiomer of Flag- $(\mathrm{C} 16)_{2}(25 \mu \mathrm{M})$ and Flag-(C14-NBD) $2(100 \mu \mathrm{M}, 2 \mathrm{~h})$ exhibit $(\mathrm{A})$ decreased mitochondria-specific accumulation and (B) CLRP delivery for cancer suppression. These results suggest that the enzymatic conversion at mitochondria is essential for efficient mitochondria targeting. 
HeLa + Flag-(C14-NBD)
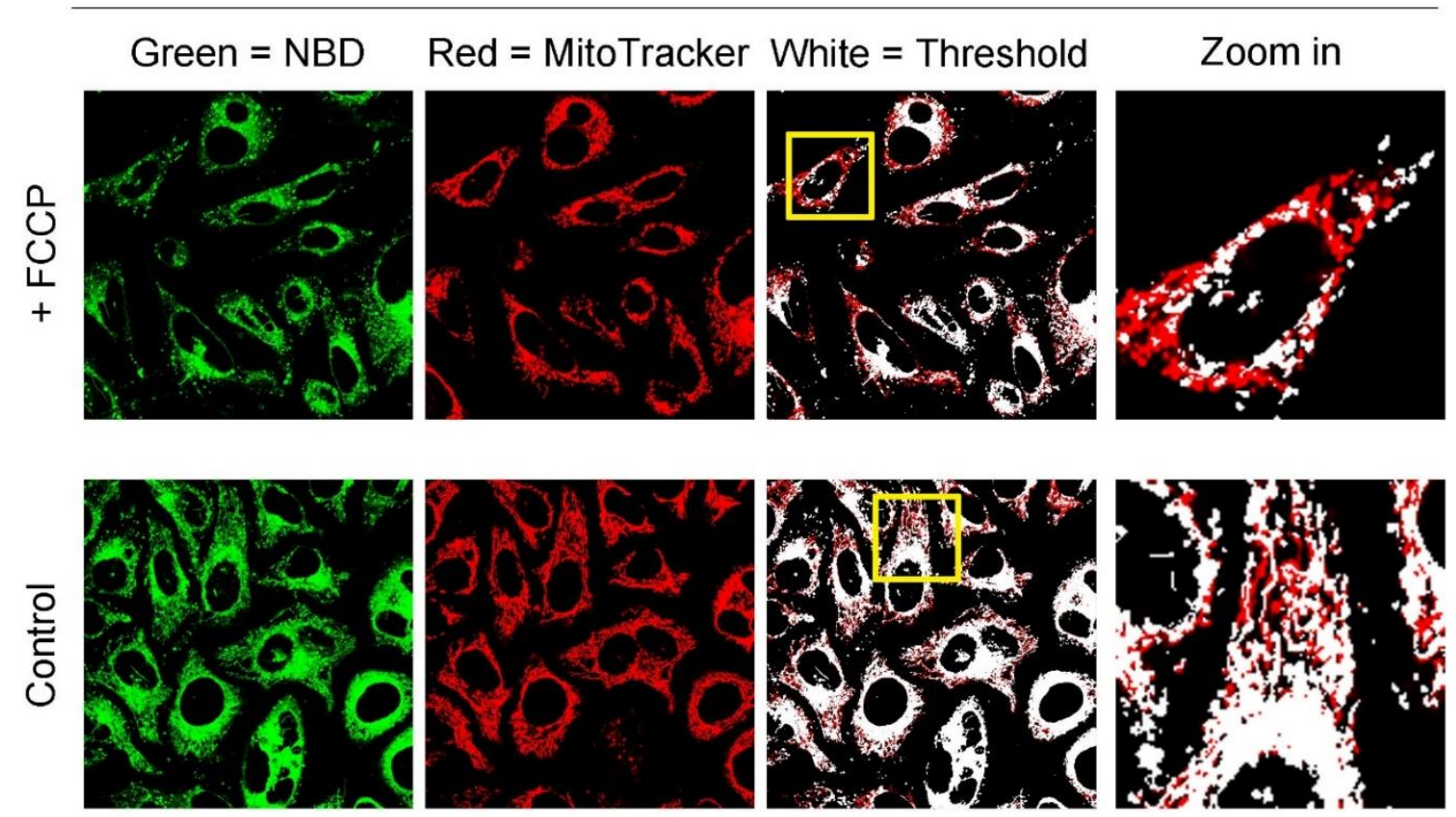

Figure S19. FCCP $(5 \mu \mathrm{M}$, pretreat $30 \mathrm{~min})$ diminishes the mitochondria targeting of Flag-(C14-NBD $)_{2}$ in Hela cells. The result suggests that the mitochondrial polarization state is critical for the Flag-tagged lipids to accumulate in mitochondria. 


\section{HeLa}

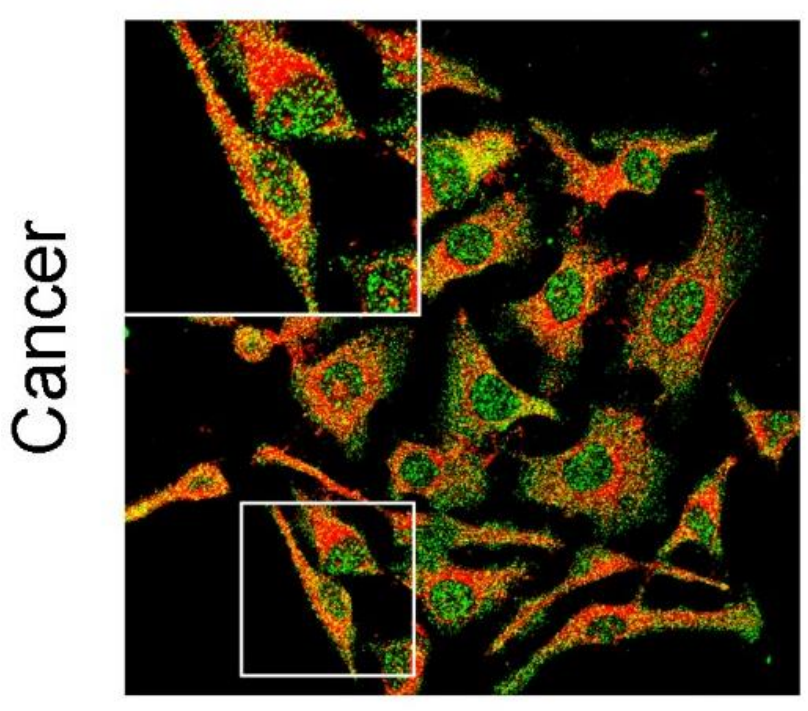

\section{HS-5}

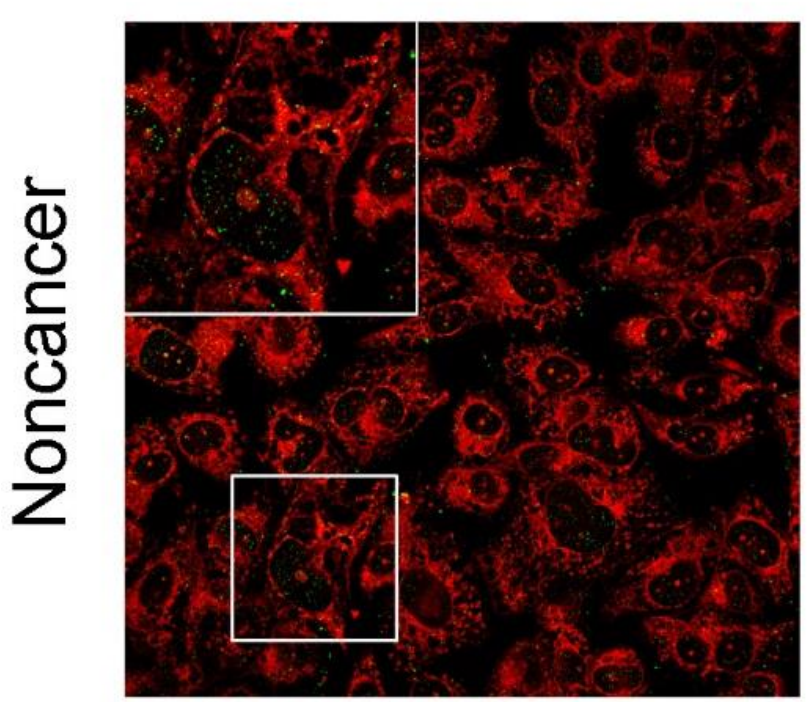

HepG2

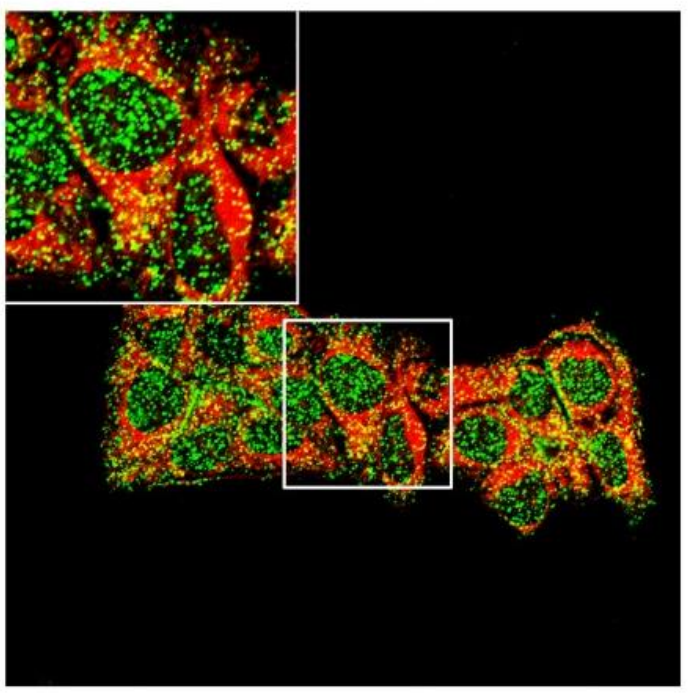

AML12

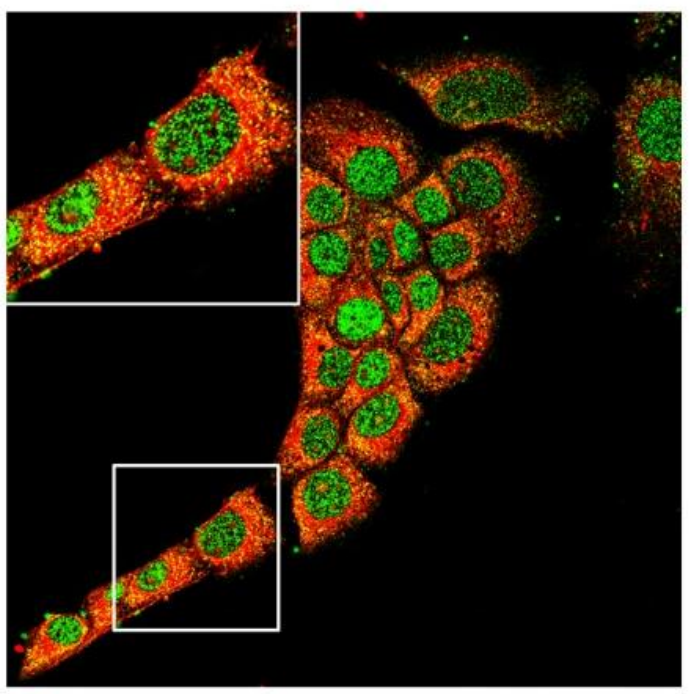

Figure S20. Immunofluorescence staining of ENTK in HeLa, HepG2, HS-5 and AML12 cells. Green = Anti-ENTK, Red = MitoTracker, Yellow $=$ overlap. 
A

HeLa cell

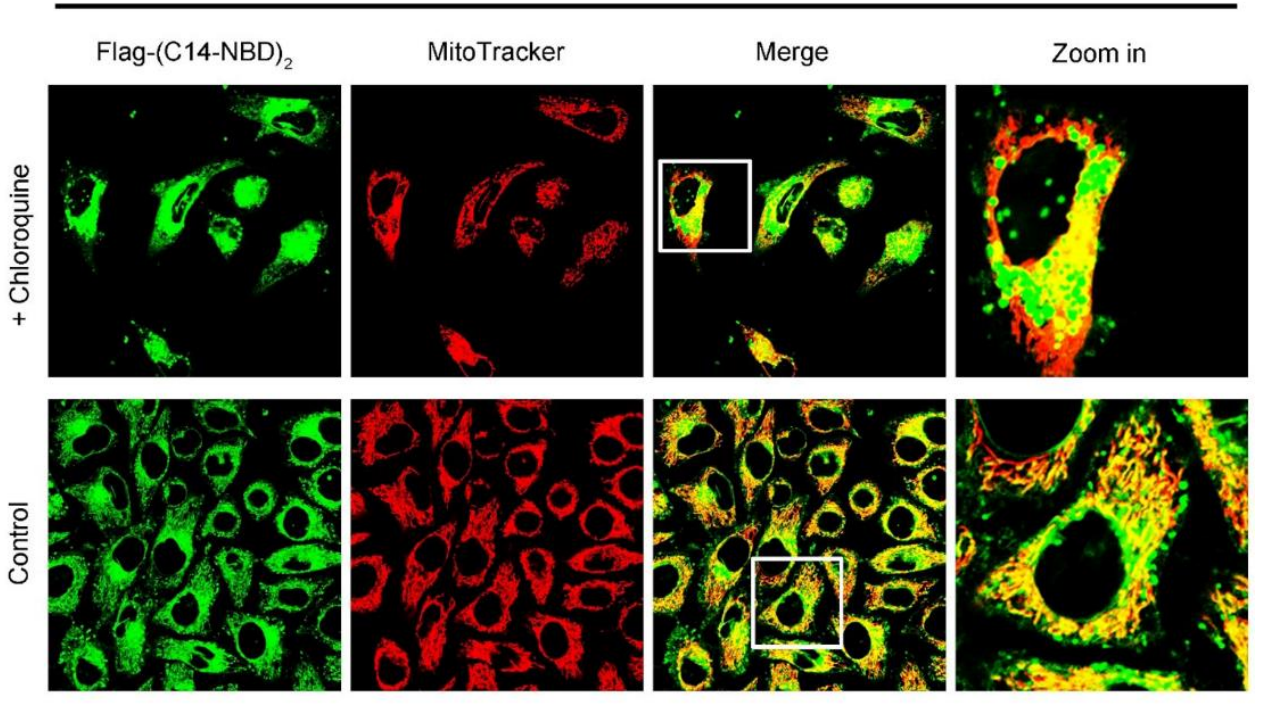

B

HepG2 cell (chloroquine pretreated)

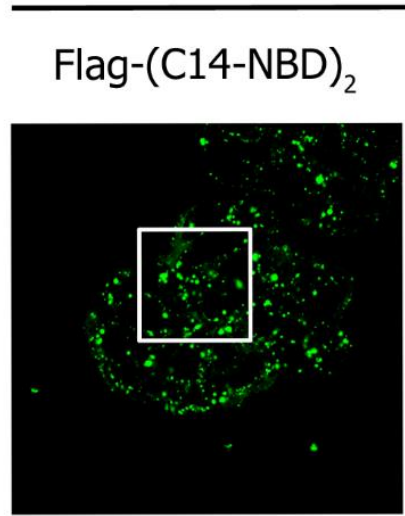

LysoTracker
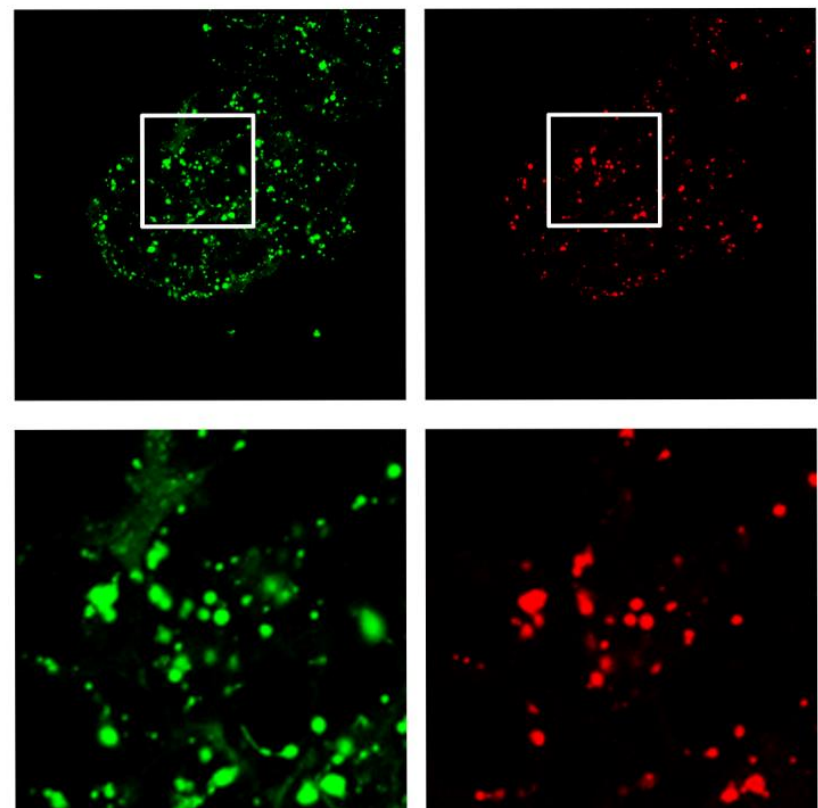

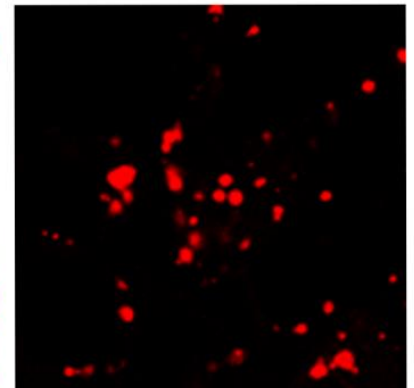

Merge
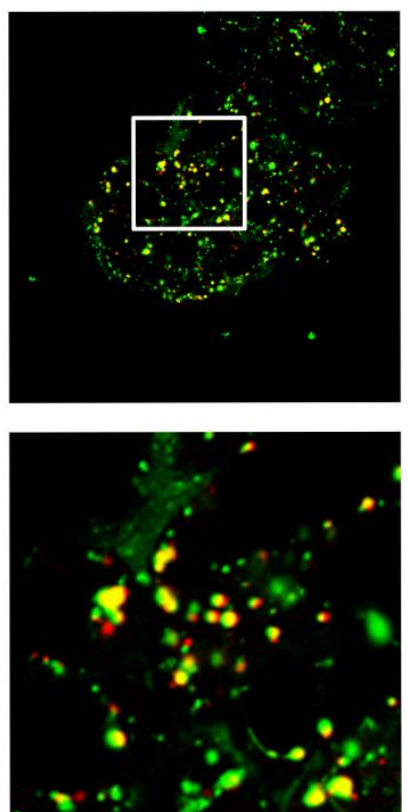

Figure S21. Chloroquine $(10 \mu \mathrm{g} / \mathrm{mL}$, pretreat $30 \mathrm{~min})$ diminishes the mitochondria targeting of Flag-(C14-NBD $)_{2}$ in cancer cells. (A) The fluorescence images of chloroquine-pretreated HeLa cells incubated with Flag-(C14-NBD)2. (B) The fluorescence images of Chloroquine-pretreated HepG2 cells incubated with Flag-(C14$\mathrm{NBD})_{2}$, the lysosomes are stained by LysoTracker. 


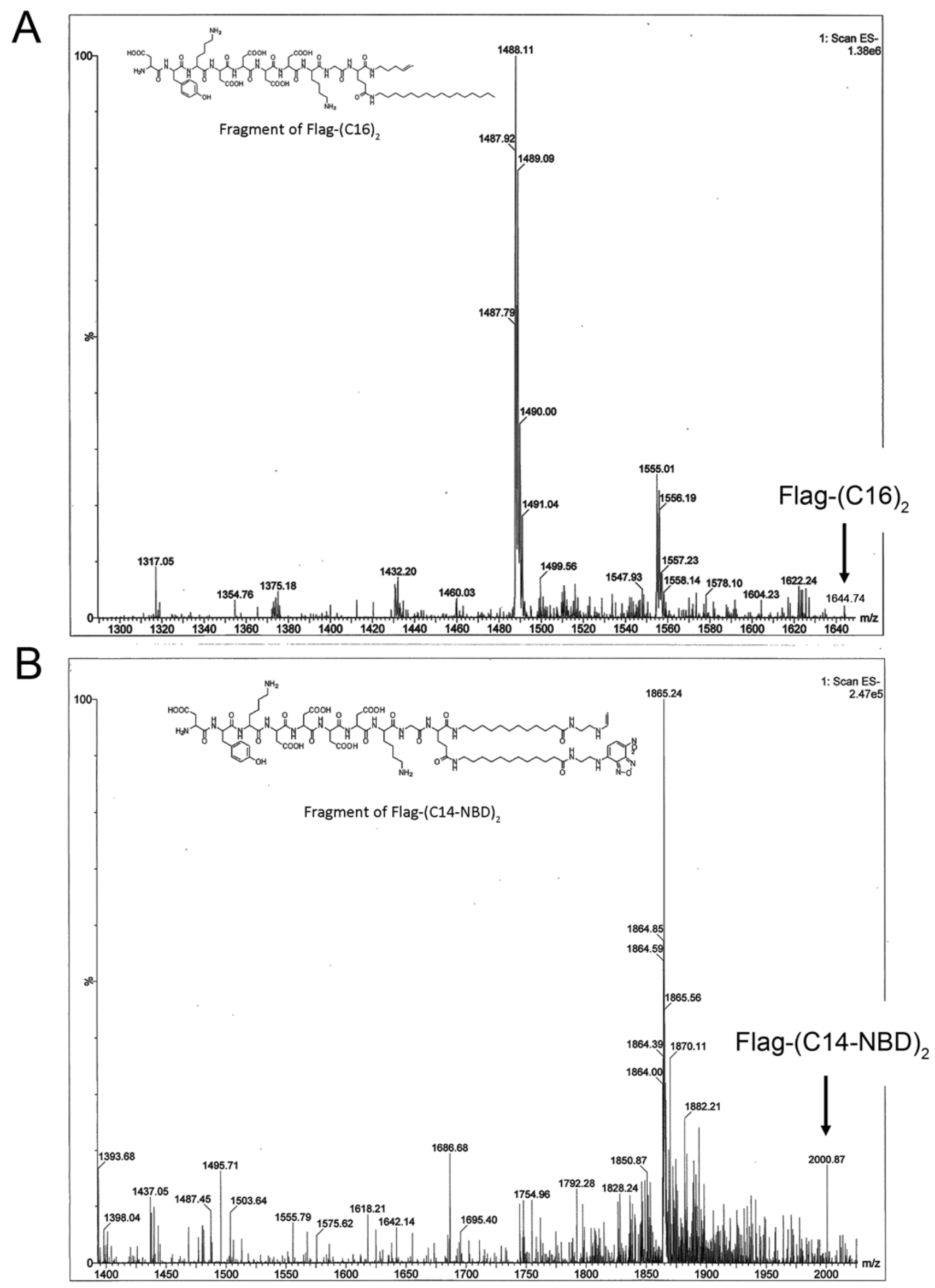

Figure S22. Mass spectrum of $(A)$ Flag- $(C 16)_{2}(M / Z=1645)$ and $(B)$ Flag- $(C 14-N B D)_{2}(M / Z=2002)$. The base peaks are the fragments of the molecules. The molecular ion peaks are indicated by arrows. 

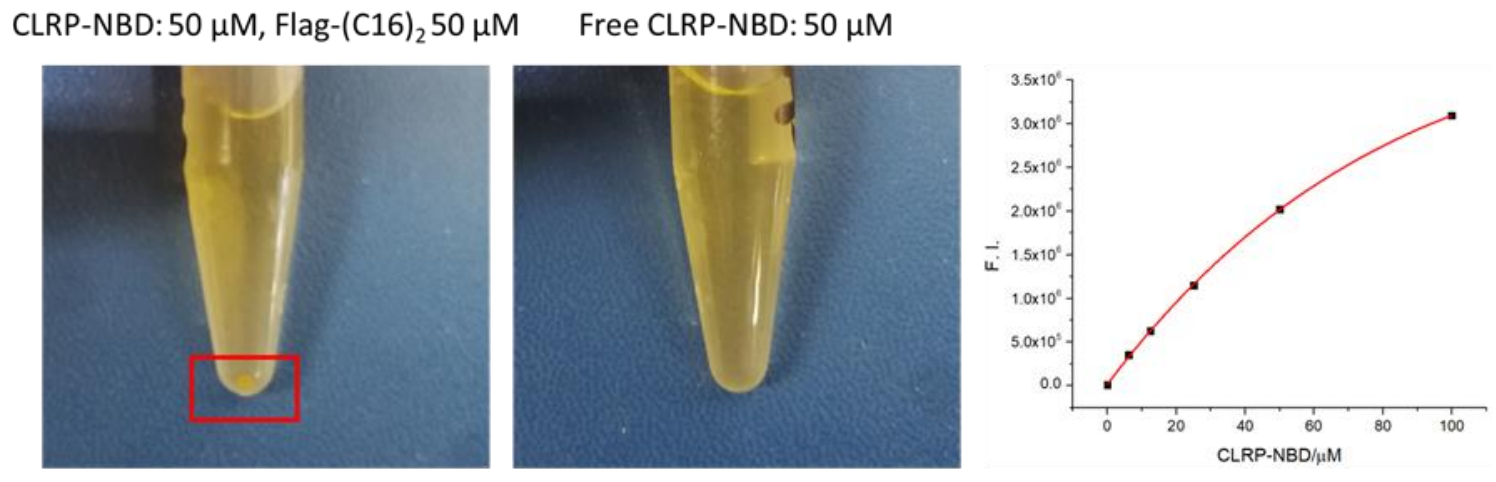

Figure S23. Optical images of free CLRPs-NBD and the mixture of CLRPs-NBD $(50 \mu \mathrm{M})$ and Flag- $(\mathrm{C} 16)_{2}(50 \mu \mathrm{M})$ after centrifuge. The concentration of CLRPs$\mathrm{NBD}$ in the supernatant was determine by fluorometer according to the standard curve.

\section{Reference}

(1) González-Rodríguez, G.; Colubi, A.; Gil, M. Á., Fuzzy Data Treated as Functional Data: A One-Way ANOVA Test Approach. Comput. Stat. Data Anal. 2012, 56, 943-955.

(2) Chen, M.; LeDuc, B.; Kerr, S.; Howe, D.; Williams, D. A., Identification of Human UGT2B7 as the Major Isoform Involved in the O-Glucuronidation of Chloramphenicol. Drug Metab. Dispos. 2010, 38, 368-375.

\section{Author Contributions}

$\mathrm{H} . \mathrm{H}$. designed and conducted the experiments and wrote the manuscript.

J. G. and X. L. helped with the synthesis of peptides.

J. W. helped with the light scattering measurement.

B. X. proposed and supervised the project, and co-wrote the manuscript with $\mathrm{H}$. $\mathrm{H}$. 